\title{
UG470
}

US $=$ CE $=6$ Proporty of tho

United States Government

\section{Bibliography of In-House and Contract Reports, Supplement 19}

Jean R. Diaz

October 1994

Approved for public release; distribution is unlimited.

\section{Research Library USACE ERDC Vicksburg, MS}

U.S. Army Corps of Engineers

Topographic Engineering Center

7701 Telegraph Road

Alexandria, Virginia 22315-3864 
31699306

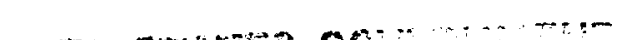

$4 G 470$

\begin{tabular}{|c|c|}
\hline REPORT DOCUMENTATION PAGE & $\begin{array}{l}\text { form Approved } \\
\text { OMB No. } 0708-0188\end{array}$ \\
\hline
\end{tabular}

Public reporting burden for this coltection of information is estimated 10 average i mour oep response, including the lime for reviewing instiuciom. searching existing dute sources.

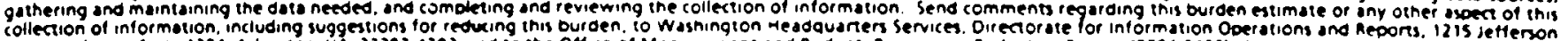

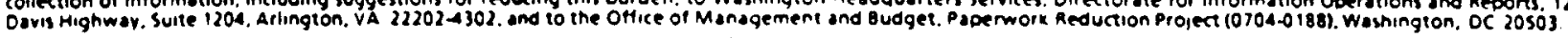

1. AGENCY USE ONLY (Leave blank)

2. REPORT DATE

October 1994

3. REPORT TYPE AND DATES COVERED

Bibliography October 1992 - October 1994

4. TITLE AND SUBTITLE

5. FUNDING NUMBERS

Bibliography of In-House and Contract Reports, Supplement 19

6. AUTHOR(S)

Jean R. Diaz

7. PERFORMING ORGANIZATION NAME(S) AND ADDRESS(ES)

U.S. Army Topographic Engineering Center

7701 Telegraph Road

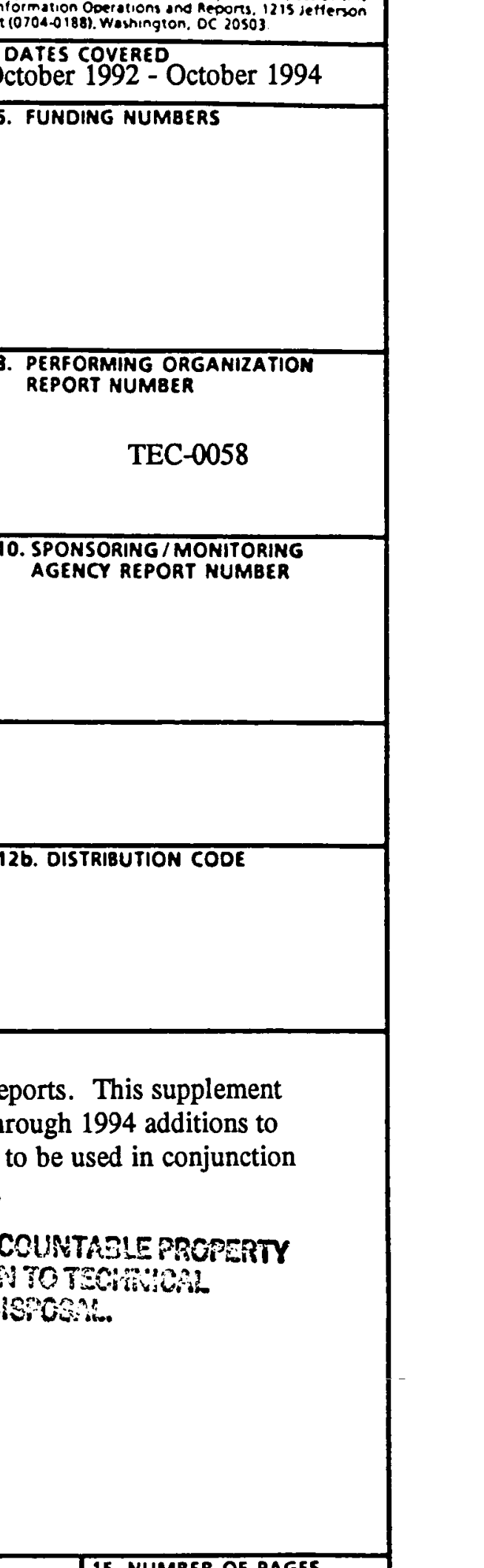

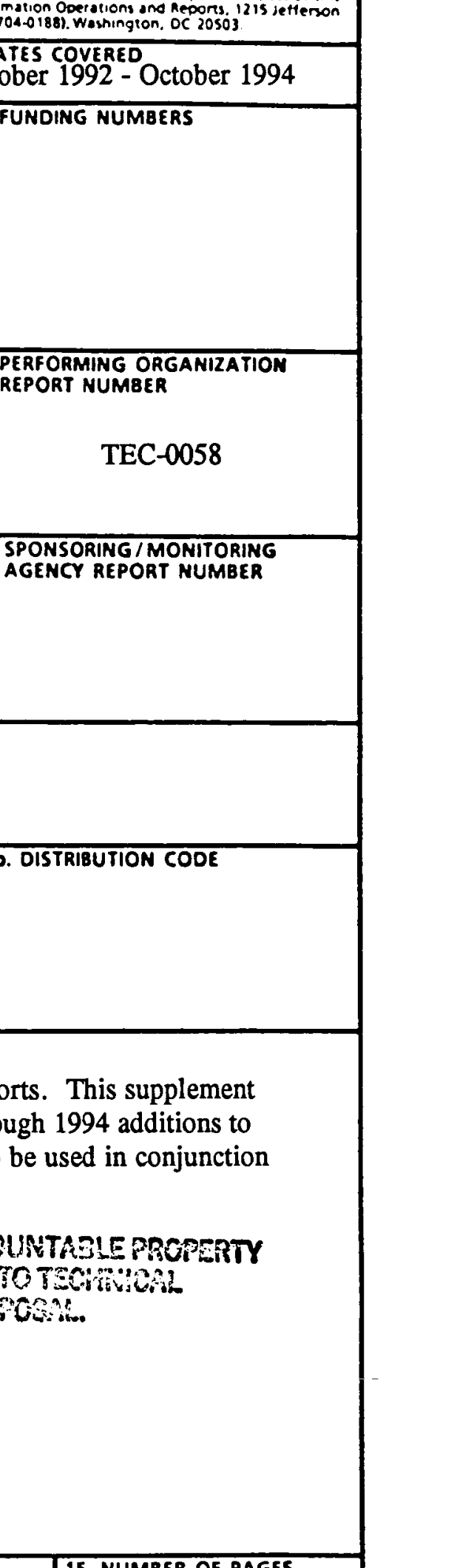

Alexandria, VA 22315-3864

9. SPONSORING/MONITORING AGENCY NAME(S) AND ADDRESS(ES)

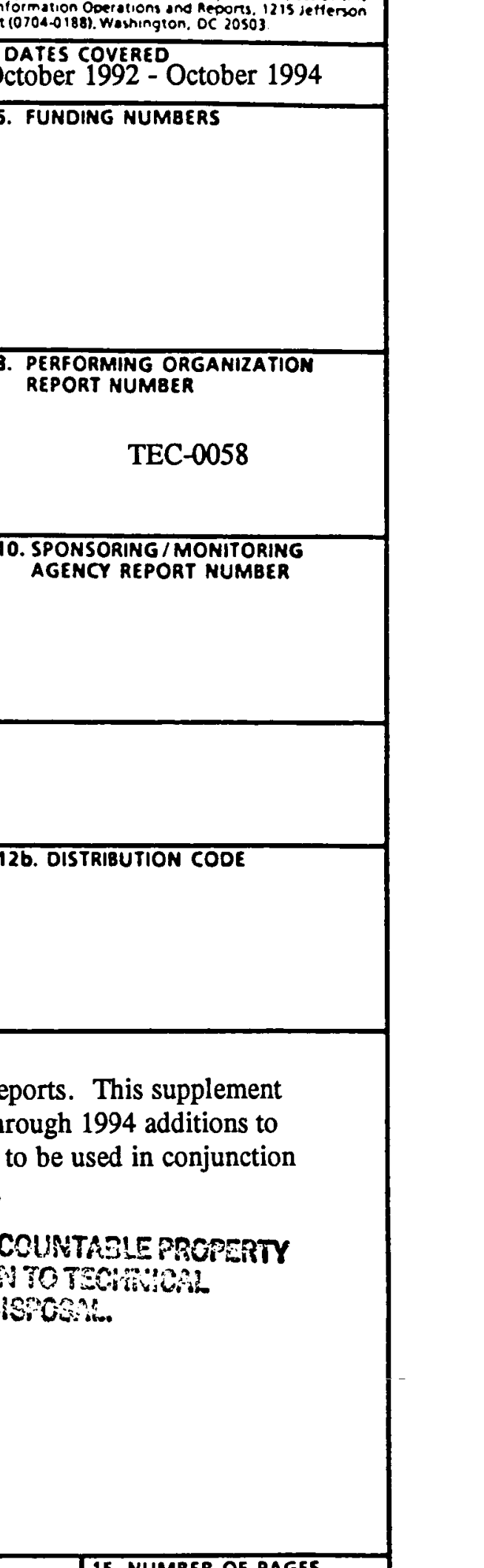

11. SUPPLEMENTARY NOTES

123. DISTRIBUTION/AVAILABILITY STATEMENT

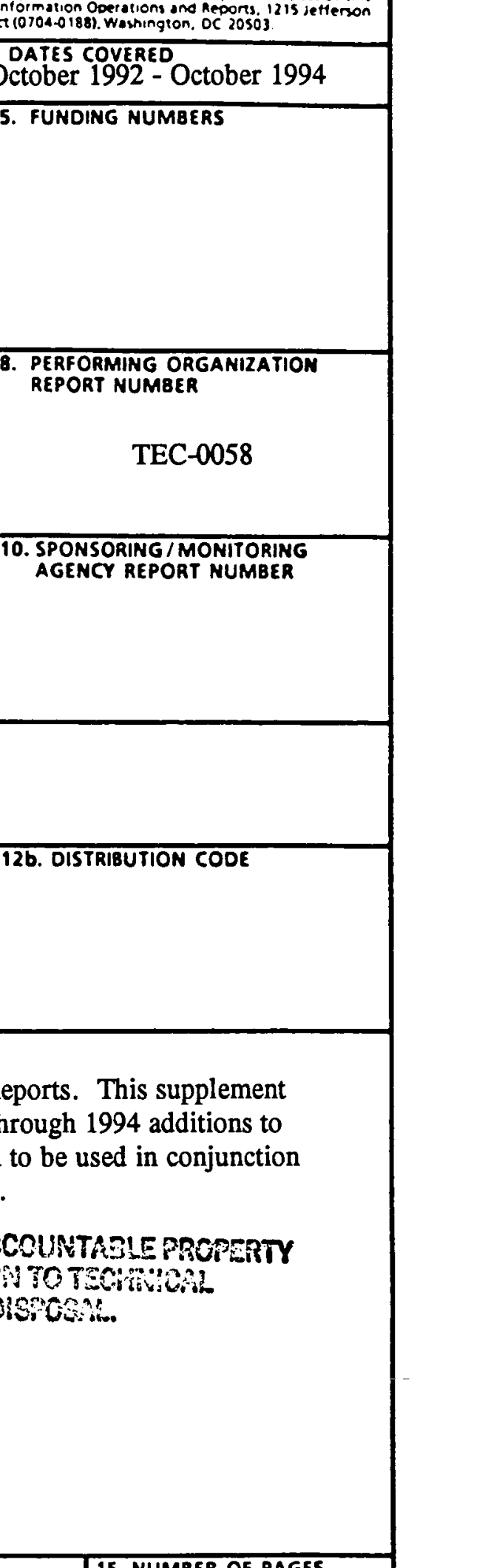

Approved for public release; distribution is unlimited.

13. ABSTRACT (Maximum 200 words)

This is Supplement 19 to the TEC Bibliography of In-House and Contract Reports. This supplement provides author and title indexes, abstracts, and AD numbers for the 1992 through 1994 additions to the continuing bibliography. It also contains a complete title index designed to be used in conjunction with the 19 published bibliographies and refers to them by year and number.

EODITS ARE ACCOUNTABLEPROPERTY

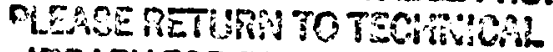

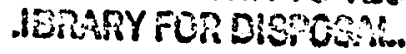

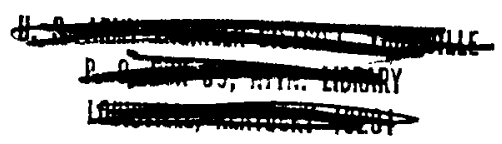

14. SUBJECT TERMS

Bibliography

Scientific Reports

0058 


\section{TABLE OF CONTENTS}

PAGE

PREFACE

v

REPORTS (Abstracts)

1

PAPERS

19

\section{INDEXES}

Titles

Corporate Authors

27

Personal Authors

29

AD Numbers

31

APPENDIX

Titles (1953 - 1994) 


\section{PREFACE}

This is Supplement 19 to the report titled, "Bibliography of In-House and Contract Reports" AD-877 653L; Supplement 1, AD-890 066L; Supplement 2, AD-905 548L; Supplement 3, AD-B005 275L; Supplement 4, AD-B010 642L; Supplement 5, AD-B019 966L; Supplement 6, AD-055 468; Supplement 7, AD-A068 744; Supplement 8, AD-A084 111; Supplement 9, AD-A099 803; Supplement 10, AD-A113 006; Supplement 11, AD-A128 400; Supplement 12, AD-A141 778; Supplement 13, AD-A160 607; Supplement 14, AD-A173 750; Supplement 15, AD-A195 953; Supplement 16, AD-A215 154; Supplement 17, AD-A252 543 and Supplement 18, AD-A265 475 . It is a continuing bibliography of reports prepared by and for the U.S. Army Topographic Engineering Center, Alexandria, Virginia. This bibliography includes reports that were published from 1 October 1992 through 1 October 1994.

Reports with $\mathrm{AD}$ numbers can be purchased by Department of Defense agencies from the Defense Technical Information Center; other agencies and individuals can purchase copies from the National Technical Information Service, Springfield, Virginia 22161-2171. Reports with a "B" in the AD number are limited in distribution to U.S. Government agencies unless permission for release is granted from the controlling office.

Mr. Walter E. Boge was Director, and Lt. Col. Louis R. DeSanzo was Commander and Deputy Director of the Topographic Engineering Center at the time of publication of this report. 


\title{
EXISTING RESOURCES, STANDARDS, AND PROCEDURES FOR PRECISE MONITORING AND ANALYSIS OF STRUCTURAL DEFORMATIONS - VOLUME I \\ September 1992
}

\author{
Adam Chrzanowski \\ Saverio Avella \\ Chen Yong-qi \\ James M. Secord \\ University of New Brunswick
}

DAAL03-91-C-0034

Keywords: Deformation Monitoring, Deformation Analysis, Dam Deformations

This report is based on a review of literature, international reports, and results of a questionnaire sent to national representatives of about 70 countries to the International Commission on Large Dams. The study focused on monitoring and analysis of deformations of large dams. The main conclusions of the study are: (1) There are no available standards and specifications in any of the reviewed countries which could be recommended for direct adaptation to dam deformation monitoring in the United States; (2) With the recent technological developments in both geodetic instrumentation, at a cost one may achieve almost any, practically needed, instrumental resolution and precision, full automation, and virtually real-time data processing; (3) Over the past 10 years there has been significant progress in the development of new methods for the geometrical and physical analyses of deformation surveys. However, due to a lack of an interdisciplinary cooperation and insufficient exchange of information, the developments have not yet been widely adapted in practice; and (4) Generally, the overall qualifications and educational background of the personnel placed in charge of monitoring surveys in the U.S. seem to be inadequate, particularly in the areas of data processing and analyses.

TEC-0026

AD A261 693

\section{U.S. ARMY EVALUATION OF THE ELECTRONIC MAP DATA (EMD) PROTOTYPE December 1992}

John P. Bradley

Keywords: Map Background, Raster, Color Separates, Resolution, Color Normalization, Declutter

This report provides a consolidated U.S. Army evaluation of the Electronic Map Data (EMD) prototype. This prototype was developed by the Digital Concepts and Analysis Center (DCAC) of the U.S. Army Topographic Engineering Center (TEC). The intent of this prototype was to refine Army map background requirements by providing a real example of an alternative product. Participants in the evaluation included program managers and support contractors representing the Army components, government agencies, and private industry. Overall, evaluator comments indicated that EMD, as defined by the prototype, cannot be definitively recommended as the Army's standard map background product. Although the color separate approach does not provide desirable capabilities not afforded by a composite image map, these advantages are outweighed by inherent limitations associated with decluttering by color. From user feedback indications, the original documented map background requirement submitted to the Defense Mapping Agency, which was for a product that contains declutterable feature data, requires minimal storage, and provides normalized color across map sheets, remains unchanged. 


\section{STATISTICAL ANALYSIS OF GEOMORPHIC, PETROGRAPHIC AND STRUCTURAL CHARACTERISTICS OF THE DARTMOOR TORS, SOUTHWEST ENGLAND May 1993}

Judy Ehlen

Keywords: Map Background, Raster, Color Separates, Resolution, Color Normalization, Declutter

The granite tors on Dartmoor are characterized and described by a combination of 21 geomorphic, petrographic and structural variables using two statistical approaches: analysis of significant correlations and multivariate analyses. Whereas an analysis of correlations enables relations between pairs of individual variables to be determined, the multivariate procedures addresses all variables at the same time. Spearman's rank correlation coefficient was used to correlate the variables so that nominal and ordinal variables could be included. The characteristics of summit tors and spur tors were defined by analyzing the significant correlations as well as by analyzing indirect relations between related variables. The multivariate procedures separated the sample of 58 tors into five clusters. Principal coordinates analysis and a non-hierarchical classification were used to determine the characteristics of each cluster. The joint spacing frequency distributions for the clusters were compared to determine statistically significant differences between them; each group is significantly different from at least two others. Comparing the results of the two procedures indicated that although all variable types are important to landform development, the geologic factors are most important. The most important variable types are rock texture, grain size, composition and structure.

TEC-0028

AD A282 904

\section{VISION-BASED NAVIGATION FOR AUTONOMOUS GROUND VEHICLES May 1992}

Larry S. Davis

Daniel DeMenthon

University of Maryland

DACA76-88-C-0008

Keywords: Border Following, Graph Matching, Hough Transforms, Matrix Operations, Parallel Search, Path Planning, Pose Estimation, Pyramids, Quadtrees, Range Imagery, Road Following, Terrain Navigation

This report describes research on ground navigation, dynamic visual surveillance, parallel vision, parallel search, and parallel matrix operations. Specific problems addressed include planning safe paths on terrain, estimating range shadows, road reconstruction, dynamic object pose estimation and tracking, quadtree and pyramid algorithms, border following, Hough transformation, and graph matching. 


\title{
IMAGE UNDERSTANDING ARCHITECTURE FINAL REPORT
}

September 1991

\author{
Charles C. Weems \\ Martin Herbordt \\ Edward M. Riseman \\ Allen R. Hanson \\ Michael Scudder \\ Deepak Rana
}

James Burrill

University of Massachusetts

DACA76-86-C-0015

Keywords: Image Understanding Architecture, Knowledge-Based Vision, Real-Time Computer Vision, Software Simulator, Parallel Processor

The primary goal of the Image Understanding Architecture (IUA) project was to build a proof-of-concept prototype of a 1/64th slice of a parallel architecture to support real-time, knowledge-based image understanding, and develop the software support environment that will be needed to utilize the hardware. The unique feature of the IUA is that it tightly couples three distinctly different parallel architectures whose capabilities are matched to the computational requirements of the three primary levels of abstraction in knowledge-based computer vision. The low-level processor (CAAPP) is a SIMD cellular array designed to perform sensory preprocessing. The intermediate-level processor (ICAP) is intended to support computation on symbolic data that has been extracted from the images or instantiated from stored models. The high-level processor (SPA) supports the general knowledge-based processing which employs multiple strategies to form an interpretation of a scene. The majority of the hardware effort has taken place at Hughes Research Laboratories, Malibu, Califormia, although UMass has principle responsibility for the design of the IUA architecture. UMass has also undertaken some smaller portions of the hardware development (the feedback concentrator for the low and intermediate-level arrays, and the communications router for the intermediate-level array). The majority of the software effort took place at UMass, although Hughes was also involved in some software development, both in support of their hardware efforts, and in the form of algorithm development for specific applications on the IUA. 


\title{
DEVELOPMENT OF A STATISTICAL METHOD FOR THREE-DIMENSIONAL TERRAIN ELEVATION ERROR ANALYSIS \\ October 1991
}

\author{
Marshall B. Faintich \\ David J. Dermody \\ TRIFID Corporation
}

DACA76-91-C-0002

Keywords: Digital Terrain Data, Digital Elevation Models, Error Analysis, Tactical Decision Aids, Command and Control

Most DoD users are not familiar with the accuracy limitations of the Digital Terrain Elevation Data (DTED) as a result of the specification limitations, the materials used in DTED production, the production processes employed in the generation of DTED, and is in general, unaware of existing and conceptual methodologies for the accuracy evaluation of DTED. This unawareness of DTED limitations may lead to critical errors in the tactical decision making process. The primary application area considered in this Phase I investigation is the effect of DTED errors on Radial Terrain Masked Area (RTMA) plots. These plots are used to provide the mission planner with the ability to locate ground areas masked by terrain when viewed from any location and height. Applications of RTMA displays include both decision making on location of communication, radar, and observation towers at a command post, as well as the inverse problem of unobserved movement through terrain masked areas. Selection of the effect of DTED errors on RTMA plots was chosen to limit the scope of the Phase I effort.

TEC-0031

AD A276 817

\section{DFAD PLUS SYSTEM DEVELOPMENT \\ May 1992}

Lawrie Jordan ${ }^{1}$ John Gilmore ${ }^{2}$

Nick Faust ${ }^{1}$

'ERDAS, Inc.

DACA72-87-C-0007

'Gilmore Aerospace Corporation

Keywords: Geographic Information System, Feature Extraction, Expert System, Digital Feature Analysis Data, Multispectral Imagery

Between 1987 and 1992, ERDAS, Inc., and Gilmore Aerospace Corporation developed a prototype expert system for the update of Digital Feature Analysis Data (DFAD) based on multispectral imagery and a number of commonly available Geographic Information System (GIS) layers. A method was developed by which ERDAS GIS Modeling tools were used to simulate and validate decision rules that were then downloaded to the Ada Based Expert System Testbed (ABEST) for execution. ERDAS developed data acquisition programs for acceptance of DFAD point, line and polygon data and conversion of DFAD into the ERDAS internal polygon file structure. The information is subsequently gridded to produce a raster GIS layer. ERDAS also made improvements to a semi-automatic Digital Terrain Elevation Data (DTED) loader. 


\section{PHYSICAL CHARACTERISTICS OF SOME SOILS FROM THE MIDDLE EAST May 1993}

Judy Ehlen

Keywords: Particle Size Analysis, Middle East, Soils

This report presents soil moisture and soil texture data on 59 soil samples from eastern Saudi Arabia, Iraq and Kuwait. Very little soil moisture data are available, and although the data reported here are probably overestimates, they are reported because of the apparent lack of such data. With respect to soil texture, the soils were grouped as sandy soils or gravelly soils, and then were further subdivided using a descriptive classification based on particle size differences. A modified version of the U.S. Department of Agriculture classification was used. This classification was tested using cluster analysis. Petrographic descriptions of 11 samples are included as an appendix. Although limited, the data are reported because of an apparent interest in such data with respect to military operations in desert areas.

TEC-0033

AD A266 670

\section{PASSIVE RECOVERY OF SCENE GEOMETRY FOR AN UNMANNED GROUND VEHICLE FIRST ANNUAL REPORT May 1993}

Robert C. Bolles

SRI International

DACA76-92-C-0003

Keywords: Stereo Analysis, Evaluation of Stereo, Scene Geometry, Unmanned Ground Vehicle, Computer Vision

The primary goal of this project is to develop a passive technology for recovering scene geometry in order to support an Unmanned Ground Vehicle (UGV) operating in a general outdoor environment. We focus on our evaluation of current stereo techniques. We report the results of the first phase of this evaluation and discuss plans for the second phase. In addition, we briefly describe our progress in the following areas: development of new object tracking techniques; application of a new scene modeling technique (developed on a parallel contract at SRI) to UGV tasks; and development of two auxiliary techniques to support our research: a technique for generating synthetic stereo pairs and a technique for multiplexing imagery from a pair of moving cameras onto a single videotape. 


\title{
ARPA UNMANNED GROUND VEHICLE STEREO VISION PROGRAM AT TELEOS RESEARCH: ANNUAL REPORT April 1993
}

\author{
H. Keith Nishihara
}

Teleos Research

DACA76-92-C-0005

Keywords: Stereo Vision, Active Vision, Real-Time Vision, Unmanned Ground Vehicle, Disparity Gradients, Area Correlation

This report reviews the work done during 1992 at Teleos Research in support of ARPA's UGV program. It first gives a broad overview of Teleos' approach to studying visual perception. In particular, the concept of minimal-meaningful-measurement tools is developed as a natural methodology for allowing a higher level application process to easily influence and exploit basic measurement modalities. The sign-correlation algorithm under development at Teleos is then described in this context and the current performance benchmarks of our accelerator technology are presented. Several important results in stereo theory were obtained this year including: the development of techniques for automatically setting stereo matcher operating parameters, an analysis identifying the principal parameters affecting the magnitude of the disparity gradient effects, and a technique for improving area correlator performance in the presence of large stereo disparity gradients. Contributions were also made to the development and implementation of methods for evaluating stereo matching algorithms. UGV application specific studies were carried out in the areas of narrow-field-of-view stereo; wide field-of-view, high-resolution stereo mosaic building; stereo landmark navigation; 3-D tracking of moving objects; evaluation of hardware accelerators; and development of a low-cost mobile test facility.

TEC-0035

AD B176 996L

\section{DIGITAL TERRAIN ELEVATION DATA (DTED) RESOLUTION AND REQUIREMENTS STUDY: PHASE 2 REPORT July 1993}

Louis A. Fatale

James R. Ackeret

Jeffrey A. Messmore

Keywords: Digital Terrain Evaluation Data (DTED), Resolution, Line-of-Sight (LOS), Sigma-t, Digital Terrain Data (DTD) Requirements, Terrain Visualization, Terrain Roughness

This report is a follow-on study that evolved from U.S. Army Topographic Engineering Center (TEC) Special Report ETL-SR-6, November 1990, titled "Digital Terrain Elevation Data (DTED) Resolution and Requirements Study: Interim Report." This study provides evidence of the influence of DTED resolution (in regions with different terrain roughness) on Army terrain data applications. The report includes extensive field work and terrain visualization undertaken to investigate DTED integrity in comparison to the actual terrain, as well as comparative line-of-sight and statistical analyses of DTED Levels 1 and 2. Finally, the report offers conclusions and recommendations for future DTED production/resolution requirements. 


\section{PERSONAL NAVIGATION AND REPORTING - PHASE I (CYBERNET) August 1993}

Eric S. Yager

Cybernet Systems Corporation

DACA76-93-C-0003

Keywords: Global Positioning System, Navigation, Self-Location, GIS, Cartography, Map-Based Applications

This Phase I effort has been driven by the soldiers' need for very specific map-based software systems. A common thread running through all military operations is their reliance upon maps. Central to soldiers' ability to successfully carry out missions is their ability to accurately locate themselves in their environment. Maps provide the context for critical missions and are an intrinsic part of military operations. High-tech soldiers of the future will use sophisticated equipment in tactical environments to help ensure their success. The following objectives accomplished in Phase I are highlighted in this report: developed a plan for rapid construction of map-based applications and outlined a toolbox upon which specific map/navigation applications can be quickly developed; implemented key components of this plan, representing a vertical slice through the toolbox to demonstrate the feasibility of developing a complete map toolbox; used these components to construct a typical application, a prototype Personal Navigation System, and demonstrate this application on desktop and portable platforms, validating this approach; created a plan to develop and implement the remainder of the toolbox as part of Phase II activities; and identified several commercial paths for transitioning the resulting technology in map-based products.

TEC-0037

AD B177 200L

\section{PERSONAL NAVIGATION AND REPORTING - PHASE I (LEVI) \\ August 1993}

Robert W. Levi

Lloyd C. Matthews

Robert Levi Associates

DACA76-93-C-0002

Keywords: Navigation, Data Links, Digital Maps, GPS, Position Locating, Dead Reckoning

The concept developed in this project is intended to provide the dismounted soldier with an autonomous low-cost navigation aid and a means for automatic reporting of individual locations to commanders. Three independent navigation aids are used to avoid dependence on a single method: Global Positioning System (GPS), dead reckoning and digital maps. The dead reckoning system will be calibrated by the GPS receiver to produce positioning capability during GPS jamming or outage. Integrated electronic maps will provide the soldier with a reference to local terrain features, rendezvous and target locations, and friendly and enemy forces. A digital radio data link will afford a means for commanders to track the position of individuals for tactical purposes and to help prevent "friendly fire" accidents. 


\section{CONIFER TREE INFLUENCE ON DIGITAL TERRAIN ELEVATION DATA (DTED): A CASE STUDY AT DULLES INTERNATIONAL AIRPORT \\ September 1993}

Kevin R. Slocum

Keywords: Digital Terrain Elevation Data, Canopy Closure, Auto-Correlation, Modelling, Surveying

Conifer tree influence on the collection and portrayal of Digital Terrain Elevation Data (DTED) is presented. Study sites are investigated which had dense conifer canopy closure. Two separate DTED collection techniques are examined in the context of studying conifer tree influence: (1) photo source auto-correlated, and (2) photo source operator assisted (floating dot). Field surveying is the mechanism used for collecting accurate, verifiable ground elevation data subsequently compared against the elevations of corresponding DTED positions. Estimated conifer tree stand heights (at the time of DTED photo source) are compared against the difference in value between DTED and field surveyed elevations. A close relationship between stand height and difference values demonstrates the potential for conifer tree height inclusion within DTED "ground" elevations. Terrain modelling impacts caused by the addition of tree heights within the DTED are addressed.

TEC-0039

AD A274 142

\section{MULTIVARIATE SPECTRAL ANALYSIS TO EXTRACT MATERIALS FROM MULTISPECTRAL DATA \\ September 1993}

Robert S. Rand

Donald A. Davis

Keywords: Bayesian Discriminant, Mahalanobis Distance, Euclidean Distance, Supervised Classification, Sub-Pixel Demixing, Mixture Analysis, Linear Models, Linear Regression

This effort investigates various multivariate analysis techniques for classification/identification to extract natural and man-made features reliably from broad-band spectral imaging data/multispectral imagery. An enhanced Bayesian method is proposed and demonstrated to exhibit increased accuracy over three conventional supervised classifiers. Broad-band spectral properties of various materials are examined and the perturbations on spectra of pure materials introduced by mixtures are shown. A mixing model that uses multiple linear regression constrained by two physical properties is tested. 


\section{PROJECT OSTRICH - A FEASIBILITY STUDY: DETECTING BURIED MINES IN DRY SOILS USING SYNTHETIC APERTURE RADAR September 1993}

John V.E. Hansen

Judy Ehlen

Timothy D. Evans

Richard A. Hevenor

Keywords: Ground-Penetrating SAR, Radar, Dry Soils, Minefield Detection, Buried Objects

Metallic and nonmetallic mines were used to construct a minefield in arid soil at Twentynine Palms, California to assess the extent to which long-wavelength radar could be used to detect buried mines by remote sensing. Surface and subsurface mines were placed in accordance with known enemy doctrine, and the site was imaged with X-, Cand L-band radar from a Navy P-3 aircraft. This report describes the construction and physical characteristics of the test sites, and presents and discusses the results of imagery analysis.

TEC-0041

AD A276 658

\section{SELECTION OF CLIMATE STATION DATA USING CLUSTERING AND TRIANGULATED IRREGULAR NETWORK TECHNIQUES \\ October 1993}

Kevin R. Slocum

Keywords: Correlation, Clustering, Triangulated Irregular Networks, Climatology, Modeling

This report presents a methodology of adding an elevation variable to the process of selecting climate station data for computer modeling. Various techniques are used in this method which include statistical correlation of climatic variables, clustering of climate station data, and development of a triangulated irregular network (TIN) internal graphic layer with nodes representing climate station locations. Improvements to the climate station data selection process are documented. 


\section{URBAN WARFARE DIGITAL DATABASE SBIR PHASE I April 1992}

MRJ Incorporated

DACA76-91-C-0003

Keywords: Automatic Three-Dimensional Wire-Frame Modeling, Urban Terrain, Image Perspective Transformation, Digital Image Correlation

This technical report describes the development of an automatic three-dimensional wire-frame modeling system for creating image perspective transformations in urban terrain. The system creates wire-frames from imagery by reconstruction of elevations derived from registered digital stereo imagery. The process includes image feature segmentation, image correlation to produce a dense elevation matrix of one elevation value per pixel, and polygon generation from a three-dimensional triangular network of those elevations.

TEC- -0043

AD B181 085L

\section{LOW INTENSITY CONFLICT VIEWER (LIC-VIEW) PHASE I January 1992}

Amold H. Lanckton

Robert J. Geiger

Synectics Corporation

DACA76-91-C-0011

Keywords: Manually Assisted Stereo Correlation, Integrated Technologies, Urban Terrain

This_technical_report describes the development of a manually assisted stereo correlation system. The report considers developing a system which integrates the four technologies of computer graphic processing, photogrammetry, image processing, and computer vision systems for modeling and rendering urban terrain. 


\title{
IMAGE UNDERSTANDING ARCHITECTURE PROTOTYPE EVALUATION AND DEVELOPMENT \\ June 1993
}

\author{
Charles C. Weems Edward M. Riseman \\ Allen R. Hanson James Burrill \\ Martin Herbordt Michael Scudder \\ Deepak Rana
}

University of Massachusetts

DACA76-89-C-0016

Keywords: Image Understanding Architecture (IUA), Knowledge-Based Vision, Real-Time Computer Vision, Software Simulator, Parallel Processor

The primary goal of this research was to complete the development and proof-of-concept prototype of a 1/64th slice of a parallel architecture to support image understanding, and to test and evaluate the architecture so the next generation Image Understanding Architecture (IUA) can be specified. The majority of the hardware effort has taken place at Hughes Research Laboratories, Malibu, California, although UMass has principle responsibility for designing the IUA architecture and has undertaken some smaller portions of hardware development. The majority of the software effort took place at UMass. Software efforts included development of a detailed software simulator for the IUA, a FORTH interpreter, and Apply and C compilers for the low-level processor of the IUA. Also developed were run-time support libraries, diagnostics, and vision algorithms. Some effort was spent implementing the ARPA IU Benchmark and evaluating the results of the exercise. Included in this report is a summary of accomplishments, an overview of the IUA design and the trade-offs addressed in its development, the design of the intermediate level interconnection network, the design of the IUA simulator and the ARPA benchmark.

TEC-0045

AD A281 594

\section{A PARSER FOR THE ISO 8211 DATA FORMAT \\ January 1994}

Michael McDonnell

Keywords: ISO 8211, Data Parsing, Data Conversion

This report describes a library of functions that parse an ISO 8211 file and convert the parsed data into a-form useful to other programs, which can then read user data from the file. The structure of ISO 8211 files will be defined and then it will be shown how these programs interpret data in those files. Finally, an example program will be presented that reads an ISO 8211 file by using this library. 


\section{REPRESENTATION, MODELING AND RECOGNITION OF OUTDOOR SCENES FIRST ANNUAL REPORT}

November 1993

Martin A. Fischler

Robert C. Bolles

SRI International

DACA76-92-C-0008

Keywords: Machine Vision, Automated Scene Analysis, Interactive Scene Analysis, Object Recognition, Terrain Modeling, Automated Cartography, Feature Extraction, Delineation, Partitioning, Geometric Modeling

The primary goal of this project was to advance the state-of-the-art in scene interpretation for autonomous systems that operate in natural terrain. In particular, techniques are being developed for representing knowledge about complex cultural and natural environments so that a computer vision system can successfully plan, navigate, recognize and manipulate objects and answer questions or make decisions relevant to this knowledge. The initial results are centered on the development of representations and associated methods for rapidly modeling natural terrain (from image sequences) at a level of organization higher than that of the conventional dense array of depths. This work will provide the essential advance needed to turn raw geometric measurements into timely information usable by robotic navigation and planning systems. Work is also progressing on two additional problems: modeling compact 3-D objects from their projected 2-D contours, and the problem of recognizing important classes of natural and man-made objects - especially roads, trees and rocks.

TEC-0047

AD A282 962

\section{VISION-BASED NAVIGATION AND RECOGNITION July 1994}

Azriel Rosenfeld

University of Maryland

DACA76-92-C-0009

Keywords: Computer Vision, Parallel Algorithms, SIMD Machines, Stereo Matching, Diffusion Processes, Image Morphing, Face Recognition, Invariants, Geometric Computations, 3-D Texture, Motion and Structure Recovery

The research summarized in this report deals with many aspects of computer vision as applied to both navigation and object recognition. In particular, this research has concentrated on eight areas: parallel algorithms for vision; diffusion processes and their roles in early vision; invariant properties and their roles in object recognition; recovery of three-dimensional scene properties from single images; recovery of observer motion and scene structure from image sequences; direct motion analysis; visual interception; and vision-based navigation. Specific topics include algorithms for image and graph computations, parallel search and stereo matching; the application of diffusion processes to image morphing and face recognition; project affine, and deformation invariants of images; reliability of geometric computations on images of three-dimensional scenes; properties of foliage regarded as a threedimensional texture; monocular and binocular recovery of motion and structure from feature correspondents in an image sequence; a unified treatment of feature-based and flow-based motion estimation; motion analysis based on global properties of the flow field; vision-based target interception; visibility on terrain; and landmark-based localization. 


\section{SMART ENVIRONMENTAL MONITOR BASED ON NEURAL NETWORKS AND MULTI-SPECTRAL PATTERN RECOGNITION September 1993}

Taiwei Lu

Physical Optics Corporation

DACA76-93-C-0004

Keywords: Neural Networks, Holographic Optical Spectral Feature Identification, Portable Smart Spectrometer, Hyperspectral Image Processing

In Phase I of this project, Physical Optics Corporation (POC) accomplished the goal of the original proposal which was to develop and optimize a unique neural network (NN) algorithm that performs rapid spectral signal processing and identification. POC's NN algorithm was tested with extremely noisy Raman spectra from Lawrence Livermore National Laboratory and experimentally showed at least ten times better sensitivity and reliability than conventional spectral signal processing methods. POC built a portable demonstration system that integrated a spectrometer with POC's NN and successfully demonstrated real-time spectral signature identification operations. POC proposed, for Phase II implementation, a holographic optical neural network (HONN) system that is capable of rapid hyperspectral imaging through an acoustic-optic tunable filter (AOTF), real-time spectral feature identification, and mapping. The success of the Phase II project will make automatic and rapid hyperspectral image analysis and feature location possible.

TEC-0049

AD A282 278

\section{FULL COLOR RECORDER}

January 1994

\section{Dean Beilke}

William Rozzi

Electronic Imaging Center

DACA76-90-C-0006

Keywords: Color, Reproduction, Image Processing, Digital, Scanner

The U.S. Army Topographic Engineering Center (TEC) initiated this program to keep abreast of new and promising color image processing and printing methods that could be used by the U.S. Army. In 1990, new non-impact printing technologies and derived products were rapidly emerging alongside high speed digital image processing capabilities. Linking these two areas held the promise of creating highly flexible digital demand color printing which had not been imagined 10 years earlier. This report studies the feasibility of creating a Full Color Recorder System from available technologies, hardware and software. The next 3 years of $R$ and $D$ under this contract produced results which have been adopted by the U.S. Army into the baseline Quick Response Multi-Color Printer system; a system designed to provide troops' real-time terrain graphic images in the field. This final report documents the rationale, history, processes, technologies and results of this program. 


\title{
ROBUST IMAGE UNDERSTANDING - TECHNIQUES AND APPLICATIONS October 1993
}

\author{
Azriel Rosenfeld \\ University of Maryland
}

DACA76-89-C-0019

Keywords: Edge Detection, Slope Estimation, Robust Estimation, Bayesian Estimation, Matching, Segmentation, Shape Recognition, Recovery, Pose Estimation

The research for this report deals with the following topics: feature detection, including both edge detection and line slope estimation; robust and Bayesian estimation of image parameters; image and pattern matching; region segmentation and shape recognition; shape recovery and pose estimation; robot hand-eye coordination; robot navigation and path planning; visibility and navigation on terrain; motion transparency and motion parameter estimation; structure from motion, using both feature-based and normal-flow-based methods and regularization techniques.

TEC-0051

AD A277 460

\section{COOPERATIVE AUTONOMOUS AGENTS TESTBED November 1993}

\author{
S.Y. Harmon M.D. Howard \\ D.M. Keirsey J.A. Krozel \\ D.W. Payton D.Y. Tsend \\ S.C. Yang
}

Hughes Research Laboratories

DACA76-89-C-0002

Keywords: SAFOR, SIMNET, DIS, Intelligent Agents, Cased-Based Reasoning, SOAR, Behavior-Based Control, Reactive Planning, Machine Leaming

The goal of the Cooperative Autonomous Agents Testbed (CAAT) program is to develop new techniques by which multiple autonomous agents operate intelligently and effectively in both cooperative or competitive modes of operation. Among the most significant accomplishments of this program are the development of two techniques that improve the effectiveness of decision making and that simplify the acquisition of tactics knowledge for computer generated forces used in large-scale distributed interactive simulations. We have developed a concurrent control paradigm that vastly improves decision making in the presence of multiple competing objectives. We have also developed case-based learning techniques to simplify the acquisition of tactics through direct interaction with subject experts. These techniques have been applied to automate simulations of Ml tank platoons as well as F-14 fighter aircraft. 


\title{
ARPA UNMANNED GROUND VEHICLE STEREO VISION PROGRAM March 1994
}

\author{
H. Keith Nishihara \\ J. Brian Burns \\ Stanley J. Rosenschein Hans Thomas \\ Matthew Turk Monnett Soldo
}

Teleos Research

DACA76-92-C-0005

Keywords: Shape Recognition, Active Vision, UGV

This report documents work carried out at Teleos Research in support of the UGV Demo II mission. This research has been divided between basic studies relating to binocular stereo, shape recognition and technology development. Teleos' approach to the study of visual perception embodies a strategy for focusing on the minimal form of perceptual measurement that is meaningful or useful. Several new stereo techniques were developed under this research program including a way to automatically set stereo matcher operating parameters, an analysis of stereo disparity gradients, and a method for improving area correlator performance in the presence of disparity gradients. Several new techniques for shape detection and recognition are reported. An active vision system for tracking moving objects applies results from the stereo and shape recognition work. A number of efforts were directed at supporting the UGV mission, including the use of narrow-field-of-view stereo for vehicle navigation; very highresolution wide-field-of-view stereo to support landmark-based navigation; test data collection for comparison and performance evaluation; and collaborative efforts with the other UGV stereo contractors at SRI and Joint Precision Labs to foster technology transfer.

TEC-0053

AD A266 670

\section{PASSIVE RECOVERY OF SCENE GEOMETRY FOR AN UNMANNED GROUND VEHICLE SECOND ANNUAL REPORT March 1994}

Robert C. Bolles

SRI International

DACA76-92-C-0003

Keywords: Stereo Analysis, Evaluation of Stereo, Scene Geometry, Unmanned Ground Vehicle, Computer Vision

The primary goal of this preject is to develop-a passive technology for constructing three-dimensional descriptions of outdoor scenes to support the navigational needs of an Unmanned Ground Vehicle (UGV) operating both during the day and at night. This report describes the development of a technique for increasing the resolution and robustness of passive range images by integrating stereo and motion analysis. Also, the development of a scene sketching framework for describing the semantic, as well as geometric properties of a scene, will significantly increase the information provided to a navigation path planner. The first step is taken toward night-time operation by producing initial stereo results from FLIR imagery. 


\section{NON-COTS DISPLAYS: THE DISPLAY TECHNOLOGY OF THE FUTURE} June 1994

James W. Gladden

Keywords: Flat Panel Displays, 3-D Stereoscopic Displays, Head-Mounted Displays, Projection Displays, CRT Displays

The future display technology for 3-D scene generation may be found in the development of the Advanced Research Projects Agency's (ARPA) High-Definition Display Systems (HDS) program. An assessment of the HDS program was initiated from ARPA literature. The literature was supplemented as needed to provide as complete a picture of this program as possible. Over 40 references are cited. The report is intended for use in developing 3-D scene generation systems needed for fast and effective visualization of battlefield information.

TEC-0055

AD A282 796

\section{SITE MODEL-BASED IMAGE REGISTRATION AND CHANGE DETECTION - FIRST ANNUAL REPORT ON RADIUS PROJECT}

June 1994
R. Chellappa
Q. Zheng
L.S. Davis
C.L. Lin
X. Zhang
C. Rodriguez
A. Rosenfeld

University of Maryland

DACA76-92-C-0024

Keywords: Aerial Image Understanding, Change Detection, Image Analysis, Quick-Look Profile, Registration

The University of Maryland (with TASC as a subcontractor) is one of a group of institutions doing research on aerial image understanding in support of the RADIUS program. The emphasis of our research is on knowledgebased change detection (CD) using site models and the domain expertise of image analysts (IAs). We are designing a system that allows the IA to specify what are to be considered as significant changes through quick-look (QL) profiles, and to-select appropriate image understanding algorithms for detecting these changes. Before CD can be attempted, the acquired images have to be registered to the site model. Two algorithms for image registration have been developed. When no information about the camera is available, we use an efficient constrained search mechanism for image-to-image registration. When an approximate camera model is available, as in RADIUS applications, we use a fast image-to-site model registration algorithm which first projects the site model into the new image domain using the given approximate camera model, and then use five control points to do camera resection and to obtain an accurate camera mode. To enable efficient transfer of technology to the IAs, we have developed our algorithms under the RADIUS Common Development Environment (RCDE). 


\section{TECHNOLOGY REQUIREMENTS FOR MINEFIELD DETECTION FROM SPACE April 1994}

Thomas Anderson

Alan Poirier

The Futures Group

DACA76-92-C-0030

Keywords: Minefields, Space, Anti-Armor, LEO Satellite, Multispectral

An analysis of the technology requirements for minefield detection from space has produced a design for a spacebased sensor that can be used to detect anti-armor minefields. The project produced some minefield reflectance measurements to support the tactical requirements analysis. The project final report describes some potential signature phenomenology based upon several aircraft flights over an Army test range. The flights were planned to collect reflectance data with a multispectral sensor over the test minefield at Twenty-nine Palms, California. The final report describes the tactical minefield problem as experienced in five hypothetical future battlefield scenarios. The tactical requirements for a space-based minefield detection satellite are derived from the battlefield scenarios and a design is suggested for a low-cost tactical imaging satellite that satisfies that stated requirement.

TEC-0057

AD A283 361

\section{REPRESENTATION, MODELING AND RECOGNITION OF OUTDOOR SCENES SECOND ANNUAL REPORT April 1994}

Martin A. Fischler

Robert C. Bolles

SRI International

Keywords: 3Machine Vision, Automated Scene Analysis, Object Recognition, Terrain Modeling

The primary goal of this project was to advance the state-of-the-art in scene interpretation for autonomous systems that operate in natural terrain. In particular, techniques are being developed for representing knowledge about complex cultural and natural environments so that a computer vision system can successfully plan, navigate, recognize and manipulate objects, and answer questions or make decisions relevant to this knowledge. The results include the development of representations and associated-methods-for-rapidly-modeling-natural-terrain,- from multiple images, at a level or organization higher than that of the conventional dense array of depths. In particular, we have developed an approach for integration of information acquired from multiple views of a scene that uses a new class of geometric primitives; it allows easy expression of known constraints and observed data, and also allows the use of practical optimization based solution techniques. This work will provide an effective way of allowing a robotic system to incrementally build a progressively more accurate and complete model of the environment in which it is operating. Work is also progressing on the problem of recognizing important classes of natural and man-made objects - especially roads, trees, rocks, and terrain features. 


\section{MANUAL OF ENVIRONMENTAL EFFECTS, THE HORN OF AFRICA}

\section{December 1992}
M. Flood
S. Fosburgh
J. Huntley
J. Neander
J. Sullivan
E. Ward
C. Werle
T. Niedringhaus

Keywords: Environment, Topography, Climate, Operations, Systems, Personnel, Somalia, Ethiopia, Djibouti, Horn of Africa, Environmental Effects

This is the second in a series of manuals designed to provide, in a concise format, useful information on the potential environmental effects on military materiel, operations, and personnel for a specific region. In the context of this manual, the environment includes general geography, topography, weather, climate, and their effects. A section on human factors and impacts has been added to this volume. This manual focuses on the Horn of Africa (in Northeast Africa), specifically Somalia, the highlands of Ethiopia, and Djibouti. Each of the major geographic elements is covered in turn. Finally, environmental effects are provided in some detail to illustrate the various environmental impacts on military materiel, operations, and personnel.

\section{MANUAL OF ENVIRONMENTAL EFFECTS, THE COUNTRIES OF FORMER YUGOSLAVIA AND ALBANIA March 1993}
M. Flood
S. Fosburgh
J. Huntley
J. Neander
T. Niedringhaus J. Sullivan
E. Ward

Keywords: Environment, Topography, Climate, Operations, Systems, Personnel, Environmental Effects, Former Yugoslavia, Albania

This is a third in a series of manuals designed to provide in a concise format, useful information on the potential environmental effects of military materiel, operations, and personnel for a specific region. In the context of this manual, the environment includes general geography, topography, weather, climate, and their effects. This manual focuses on the countries of former Yugoslavia and Albania. Environmental effects are provided in some detail to illustrate the various environmental impacts on military materiel, operations, and personnel. 


\section{PAPERS}

ACKERET, James, "Comparative Analysis of Leveling Instruction Wild NA3000 and Zeiss NI-1," USACE Training Symposium on Surveying, Mapping, Remote Sensing, and GIS, 15-19 Aug 94, New Orleans, LA, AD-A282 155

ANDERSON, John, "Spectral Reflectance Properties of Wetland Plants," ISSSR Technology Session, 10-15 Jul 94, San Diego, CA, AD-A283 546

ARTIS, Don, "The Potential for the DOD to Use Space-Based Remote Sensing in Support of other Agencies to Manage National and World-Wide Environmental Programs," ASCE Space, 26 Feb - 3 Mar 94, Albuquerque, NM, AD-A273 615

BARR, Samuel, "Target Material Identification Using Hyperspectral Remote Sensing Technology," Multisensors \& Sensor Data Fusion Symposium, 8-11 Nov 93, Brussels, Belgium

BARR, Samuel, "Hyperspectral Image Processing," ISSSR Technology Session, 10-15 Jul 94, San Diego, CA

BENTON, John, "Using Hybrid Knowledge Bases for Missile Siting Problems," IEEE, 1-4 Mar 94, San Antonio, TX, AD-A283 553

BENTON, John, "Automated Site Selection of Air Defense Missile Batteries," Army Science Conference, 20-24 Jun 94, Orlando, FL, AD-A277 960

BLOSS, Brian, "Desert Storm: A Focus on Terrain Analysis Support," Association of America, Geography Middle States Division, Annual Meeting, 16-17 Oct 92, Syracuse, NY, AD-A254 141 \& A254 824

BROWN, Roger, "Feature Mapping in a Photogrammetric GIS," GIS/LIS Annual Conference and Exhibition, 10-12 Nov 92, CA, AD-A275 418

BROWN, Roger, "Feature Map Exchange Formats in a Photogrammetric GIS," ASPRS/ACSM, 1418 Feb 93, New Orleans, LA

BURGESS, John, "Evaluation of Various Algorithms for GPS Post Processed On-the-Fly Ambiguity Resolution," GPS, 22-24 Sep 93, Salt Lake City, UT

BURGESS, John, "The Development of GPS Controlled Photogrammetry within the Corps of Engineers," GPS, 22-24 Sep 93, Salt Lake City, UT,

CALDWELL, Douglas, and GRAFF, Linda, "Directional Regions in Geographic Information Systems," GIS/LIS Annual Conference and Exhibition, 2-4 Nov 93, Minneapolis, MN, AD-A268 536

CALDWELL, Douglas, "GIS and Comparative Geography," Environmental Systems Research Institute (ESRI) Users Conference, 23-27 May 94, Palm Springs, CA 


\section{PAPERS (continued)}

CATANIA, Luke, "Scene Rendering for the Smart Weapons Operability Enhancement Program," SPIE Conference, 12-16 Apr 93, Orlando, FL, AD-A276 503 \& A277 685

CHEN, Pi-Fuay, and TRAN, Tho Cong, "Hyperspectral Imagery Classification Using a Back Propagation Neural Network," ISSSR Technology Session, 10-15 Jul 94, San Diego, CA, AD-A273 615

CHRZANOWSKI, Adam, and FRODGE, Sally, "A Study on the World-Wide Status of Dam Deformation Monitoring \& Analysis," National Dam Society Meeting, 26-29 Sep 93, Kansas City, MO

COX, Thomas, "PPS GPS - What is it? and How do I Get it?," USACE Training Symposium on Surveying, Mapping, Remote Sensing, and GIS, 15-19 Aug 94, New Orleans, LA, AD-A281 345

DeLOACH, Stephen, "GPS Tides and Datums," USACE Training Symposium on Surveying, Mapping, Remote Sensing, and GIS, 15-19 Aug 94, New Orleans, LA, AD-A282 422

DeLOACH, Stephen, and HAGGREN, Henrik, "Application of Modern Techniques for Engineering Surveys," International Federation of Surveyors Conference, 13-18 Feb 93, New Orleans, LA

DeLOACH, Stephen, "Continuous Deformation Monitoring System," 6th Canadian Symposium on Mining \& Surveying, May 93, Banss, Alberta, Canada

EASTES, John, "A Rationale for Pixel Colorations of Evaporite Mineral Deposits in Thermal Imagery of Death Valley, CA," ISSSR Technology Session, 10-15 Jul 94, San Diego, CA

EDWARDS, Daniel, "The Use of Digital Stereo Photogrammetric Methods in Historical Photo Analysis," ASPRS/ACSM, 25-28 Apr 94, Reno, NV, AD-A275 287

FATALE, Louis, ACKERET, James, MESSMORE, Jeffrey, "Impact of Digital Terrain Elevation Data Resolutions on Applicants Stimulations vs. Reality," ASPRS/ACSM, 25-28 Apr 94, Reno, NV, AD-A253 237

FISCHER, Robert, "Dredge Volume Computation Using TIN Routines," ASCE Dredging Conference, 13-16 Nov 94, Buena Vista, FL

FOSBURGH, Bryn, "The U.S. Army Engineer Topographic Laboratories Survey Support to Operation Desert Shield/Storm"

FRANO, EDWARDS, PIERSON, ROOS, BARWICK, and McCRACKEN, "The Use of Digital Stereo Photogrammetric Methods in Historical Photo Analysis," ASPRS/ACSM, 25-28 Apr 94, Reno, NV, AD-A275 287 


\section{PAPERS (continued)}

FRODGE, Sally, AUSTIN, Andrew, PLECITY, Mark, and DENDY, Roger, "The Advanced Communications Technology Satellite for a Differential Global Positioning System," Technical Meeting, 20-22 Jan 93, San Francisco, CA, AD-A277 592

FRODGE, Sally, DeLOACH, Stephen, and REMONDI, Benjamin, "Assessment of GPS Carrier Phase Ambiguity Resolution On-the-Fly," Institute of Navigation Meeting, 30 Mar - 2 Apr 93, Amsterdam, Netherlands

FRODGE, Sally, "Results of Real-Time Testing \& Demonstration of U.S. Army Corps of Engineers Real-Time On-the-Fly Positioning System, "Institute of Navigation, National Annual Technical Meeting, 25-26 Jan 94, San Diego, CA, AD-A276 160

FRODGE, Sally, Dr. REMONDI, Dr. LAPUCHA, "Real-Time Centimeter Positioning with GPS: A System Developed by the U.S. Army Corps of Engineers," Army Science Conference, 20-24 Jun 94, Orlando, FL, AD-A278 152

FRODGE, Sally, "Augmented GPS: The Federal System," USACE Training Symposium on Surveying, Mapping, Remote Sensing, and GIS, 15-19 Aug 94, New Orleans, LA

FRODGE, Sally, SHANNON, Brian, Dr. REMONDI, Dr. LAPUCHA, and BARKER, Richard, "Results of Real-Time Testing of GPS Carrier Phase Ambiguity Resolution On-the-Fly," GPS, 22-24 Sep 93, Salt Lake City, UT, AD-A275 168

FRODGE, Sally, "The Worldwide Status of Monitoring and Analysis of Dam Deformations," 6th Canadian Symposium on Mining \& Surveying, May 93, Branaff, CN

FRODGE, Sally, "Development of Assessment of GPS Carrier Phase Ambiguity Resolution On-theFly," International Federation of Surveyors (FIG) XX Congress, 5-12 Mar 94, Melbourne, Australia

GARSTER, James, "Elevation Determination by Using GPS," USACE Training Symposium on Surveying, Mapping, Remote Sensing, and GIS, 15-19 Aug 94, New Orleans, LA, AD-A281 290

GETLEIN, Stephen, and KARALUS, Randall, "Balancing Development Water Quality and Wetland Protection," Watershed Conference, 21-24 Mar 93, Alexandria, VA

GRAFF, Linda, "An Automated Approach to Classifying Generic Terrain Features Using Digital Elevation Data," 3rd International Geomorphology Conference, 24-29 Aug 93, Ontario, CN, ADA268 385

HARDAWAY, Michael, and GARDNER, Geoffrey, "Visualization of Multiple Battlefield Obscurants," Battlefield Atmospherics Conference, 1-3 Dec 92, Fort Bliss, TX, AD-A254 236 


\section{PAPERS (continued)}

HARDAWAY, Michael, "The Smart Weapons Operability Enhancement (SWOE) Program," 45th Conference of the Society for Image Science \& Technology Military Applications of Imaging, 10-15 May 94, New Jersey

HENLEY, Ponder, EVANS, Timothy, "Spectral Characteristics (.402.5 um) \& the Detection of Camouflage Materials," ISSSR Technology Session, 10-15 Jul 94, San Diego, CA

HEVENOR, Richard, "Edge Detection Using a Complex Wavelet," SPIE'S International Symposium on Intelligence Information Systems, 4-8 Apr 94, Orlando, FL, AD-A273 699

JANK, Dale, and HALE, John, "Terrain-Based Mission Planning Workstation (TMPW), ASPRS/ACSM '93, 14-18 Feb 93, New Orleans, LA, AD-A276 569

JOY, Richard, "Reusable Software for Army Mapping, Charting, and Geodesy Applications," Federal Geographic Technology Conference, 26-28 Sep 94, Washington, DC

KIM, John, "An Efficient Algorithm for 3-D Connect-the-Dots," 8th Annual Symposium on GIS, 2124 Feb 94, Vancouver, CN, AD-A275 431

KIM, John, "High-Target Visibility Analysis," ASPRS/ACSM, 25-28 Apr 94, Reno, NV, AD-A274 805

KNOWLES, Robert, "An Integrated Approach to Groundwater Exploration in Developing Countries Using GIS \& Remote Sensing," ASPRS/ACSM, 25-28 Apr 94, Reno, NV

KNOWLES, Robert, "Military Geology in Support of Nation Assistance Exercises in Central and South America," Military Geology Symposium, 24-27 Oct 94, Seattle, WA

KNOWLES, Robert, "The Importance of Hydrogeology During the Gulf War," Geological Society of America Annual Meeting, 24-29 Oct 93, Boston, MA

KNOWLES, Robert, "The Use of GIS and Remote Sensing in Groundwater Exploration for Developing Countries," 10th Thematic Conference on Geologic Remote Sensing, 10 May 94, San Antonio, TX, AD-A284 059

KNOWLES, Robert, and WEDGE, Keith, "Military Geology Applications During the Gulf War," Geology Society of America Meeting, 24-27 Oct 94, Seattle, WA

KOKLAUNER, Karl, "Optimization of Vector Product Format Data for Map Background Display in Army Tactical Systems," ASPRS/ACSM, 25-28 Apr 94, Reno, NV, AD-A274 687

NILES, Anthony, "ECDIS Test \& Demonstration on the Mississippi River," U.S. Hydrographic Conference, 19-23 Apr 94, Norfolk, VA, AD-A283 072 


\section{PAPERS (continued)}

NORVELLE, F. Raye, "Alternatives to Hierarchical Techniques in Stereo Correlation," SPIE Annual Convention, Apr 93, Orlando, FL, AD-A276 570

NORVELLE, F. Raye, "Using Iterative Orthophoto Refinements to Generate and Correct Digital Elevation Models (DEMS)," ASPRS/MAPPS Conference, 28 Aug 94, Washington, DC, AD-A254 625

OIMEN, Daniel, "PLGR Accuracy Evaluation," Training Symposium on Surveying, Mapping, Remote Sensing, and GIS, 15-19 Aug 94, New Orleans, LA, AD-A281 291

RINKER, Dr. Jack, "Remote Sensing Tutorial - Multiband, Multi-spectral, Hyperspectral," ISSSR Technology Session, 10-15 July 94, San Diego, CA

RINKER, Dr. Jack, "Analysis of Fracture Patterns Using Remote Sensing," Military Geology Symposium, 24-27 Oct 94, Seattle, WA

ROOS, Maurits, "The Image Digitizing System," ASPRS/ACSM, 14-18 Feb 93, New Orleans, LA, AD-A275 341

RUBY, Jeffrey, "TIN Software Survey," USACE Training Symposium on Surveying, Mapping, Remote Sensing, and GIS, 16-19 Aug 94, New Orleans, LA

SIMCOX, George, "A Foundation for Fusion," 6th National Symposium on Sensor Fusion, 13-15 Apr 93, Orlando, FL, AD-A277 521

SIMENTAL, Edmundo, "Application of a Linear Least Square Model for Unmixing Hyperspectral Mix Pixels," ISSSR Technology Session, 10-15 Jul 94, San Diego, CA

SIMENTAL, Edmundo, and GONZALEZ, Elisa, "Linear Estimation of Hyperspectral Mixed Pixel Components," ISSSR Technology Session, 10-15 Jul 94, San Diego, CA, AD-A283 893

SLOCUM, Kevin, and GETLEIN, Stephen, "Watershed-Scale Wetland Characterization," USACE Training Symposium on Surveying, Mapping, Remote Sensing, and GIS, 15-19 Aug 94, New Orleans, LA

TRAN, Tho Cong, and CHEN, Pi-Fuay, "Water Regions Extraction from Radar Imagery Using a Neural Network," World Congress on Neural Networks (WCNN '93), 11-15 July 93, Portland, OR, AD-A259 517

WALKER, Jeffrey, "Caterpillar and TEC Joint Research Project: Construction Vehicle Navigation and Automation," USACE Training Symposium on Surveying, Mapping, Remote Sensing, and GIS, 15-19 Aug 94, New Orleans, LA, AD-A281 645

WERKHEISER, Anne, and PARIKH, JoAnn, "Neural Network Solutions to Logic Programs with Geometric Constraints," SPIE Conference, 4-8 Apr 93, Orlando, FL, AD-A275 419 


\section{PAPERS (continued)}

WERKHEISER, Anne, and PARIKH, JoAnn, "Incorporating Geometric Constraints into Rule-Based Systems Using Non-Linear Optimization," World Conference on Expert Systems, 10-14 Jan 94, Lisbon, Portugal, AD-A275 093

WITTE, Tom, "An Experiment Integrating GPS Tracking Video Imaging and 3-D Stimulation," ASPRS/ACSM, 25-28 Apr 94, Reno, NV, AD-A275 538

WITTE, Tom, "Exploitation of Stereophotogrammetrically Derived 3-D Wireframe Models to Produce Urban Simulations," ASPRS/ACSM, 25-28 Apr 94, Reno, NV, AD-A275 538

WITTE, Tom, and KELLY, Valerie, "Visualization Support for an Army Reconnaissance Mission," ASPRS/ACSM, 25-28 Apr 94, Reno, NV, AD-A275 522 


\section{TITLES}

TITLE

PAGE

ARPA Unmanned Ground Vehicle Stereo Vision Program $\quad 15$

ARPA Unmanned Ground Vehicle Stereo Vision Program at Teleos Research:

Annual Report

Conifer Tree Influence on Digital Terrain Elevation Data (DTED): A Case Study at Dulles International Airport

Cooperative Autonomous Agents Testbed

Development of a Statistical Method for Three-Dimensional Terrain Elevation Error Analysis

$\begin{array}{ll}\text { DFAD Plus System Development } & 4\end{array}$

Digital Terrain Elevation Data (DTED) Resolution and Requirements Study: 6 Phase 2 Report

Existing Resources, Standards, and Procedures for Precise Monitoring and Analysis of Structural Deformations - Volume I

Full Color Recorder

Image Understanding Architecture Final Report 3

Image Understanding Architecture Prototype Evaluation and Development 11

$\begin{array}{lr}\text { Low Intensity Conflict Viewer (LIC-VIEW) Phase I } & 10\end{array}$

Manual of Environmental Effects, The Countries of Former Yugoslavia and Albania 18

$\begin{array}{lr}\text { Manual of Environmental Effects, The Horn of Africa } & 18\end{array}$

$\begin{array}{ll}\text { Multivariate Spectral Analysis to Extract Materials from Multispectral Data } & 8\end{array}$

Non-COTS Displays: The Display Technology of the Future 16

Parser for the ISO 8211 Data Format, A 11

Passive Recovery of Scene Geometry for an Unmanned Ground Vehicle, First 5 Annual Report 


\section{TITLES (continued)}

\section{TITLE}

PAGE

Passive Recovery of Scene Geometry for an Unmanned Ground Vehicle, Second

Annual Report

Personal Navigation and Reporting - Phase I (Cybernet)

Personal Navigation and Reporting - Phase I (Levi)

Physical Characteristics of Some Soils from the Middle East

Project Ostrich - A Feasibility Study: Detecting Buried Mines in Dry Soils Using Synthetic Aperture Radar

Representation, Modeling and Recognition of Outdoor Scenes, First Annual Report

Representation, Modeling and Recognition of Outdoor Scenes, Second Annual Report

Robust Image Understanding - Techniques and Applications

Selection of Climate Station Data Using Clustering and Triangulated Irregular Network Techniques

Site-Model Based Image Registration and Change Detection - First Annual Report on Radius Project

Smart Environmental Monitor Based on Neural Networks and Multi-Spectral Pattern Recognition

Statistical Analysis of Geomorphic, Petrographic and Structural Characteristics of the Dartmoor Tors, Southwest England

Technology Requirements for Minefield Detection from Space

Urban Warfare Digital Database SBIR Phase I

U.S. Army Evaluation of the Electronic Map Data (EMD) Prototype 1

Vision=Based Navigation and Recognition 


\section{CORPORATE AUTHORS}

NAME

PAGE

Cybernet Systems Corporation

7

Electronic Imaging Center

13

ERDAS, Inc.

4

Futures Group, The

Gilmore Aerospace Corporation

4

Hughes Research Laboratories

14

MRJ Incorporated

10

Physical Optics Corporation

Robert Levi Associates

SRI International

$5,12,15,17$

Synectics Corporation

Teleos Research

6,15

TRIFID Corporation

4

University of Maryland

$2,12,14,16$

University of Massachusetts

3,11

University of New Brunswick 


\section{PERSONAL AUTHORS}

NAME

Ackeret, James R.

Anderson, Thomas

Avella, Saverio

Beilke, Dean

Bolles, Robert C.

Bradley, John P.

Burns, Brian J.

Burrill, James

Chellappa, $\mathbf{R}$.

Chrzanowski, Adam

Davis, Donald A.

Davis, Larry S.

DeMenthon, Daniel

Dermody, David J.

Ehlen, Judy

Evans, Timothy D.

Faintich, Marshall B.

Fatale, Louis A.

Faust, Nick

Fischler, Martin A.

Flood, Mark

Fosburgh, Sheryl

Geiger, Robert J.

Gilmore, John

Gladden, James W.

Hansen, John V.E.

Hanson, Allen R.

Harmon, S.Y.

Herbordt, Martin

Hevenor, Richard A.

Howard, M.D.

Huntley, Jack

Jordan, Lawrie

Keirsey, D.M.

Krozel, J.A.
PAGE

6

17

1

13

$5,12,15,17$

1

15

3,11

16

1

8

2,16

2

4

$2,5,9$

9

4

6

4

12,17

18

18

10

4

16

9

3, 11

14

3, 11

9

14

18

4

14

14
NAME

PAGE

Lanckton, Arnold H.

10

Levi, Robert W.

Lin, C.L.

Lu, Taiwei

7

16

13

Matthews, Lloyd C. $\quad 7$

McDonnell, Michael 11

Messmore, Jeffrey A.

6

Neander, John

18

Neidringhaus, Thomas

18

Nishihara, Keith H.

6,15

Payton, D.W.

14

Rana, Deepak 3, 11

Rand, Robert S.

Riseman, Edward M.

8

Rodriguez, C.

3,11

Rosenschein, Stanley J.

16

Rosenfeld, Azriel

Rozzi, William

$12,14,16$

13

Scudder, Michael

3,11

Secord, James $M$.

Slocum, Kevin R.

Soldo, Monnett

Sullivan, Jeff

8,9

15

18

Thomas, Hans 15

Tsend, D.Y.

Turk, Matthew

Ward, Elizabeth

18

Weems, Charles C.

3,11

Werle, Carolyn

18

Yager, Eric S.

7

Yang, S.C.

Yong-qi, Chen

Zhang, $\mathrm{X}$.

16

Zheng, $Q$.

16 


\section{APPENDIX - TITLES}

1953 - 1994 
Accuracy of Cartometric Data

Accurate Emphemeris Time Determination and

ETL-RN-72-4

Geocentric Stations Position from Photographs of the Moon Against Stellar Background

Acousto-Optic Technology for Topographic

Feature Extraction and Image Analysis

Adjunct Development Test II (DT II) of Position

and Azimuth Determining System AN/USQ-70

Acquisition and Evaluation of Thermal Standard Data

ADRIES Prototype System Development Program (1986-1990)

Advanced Continuous Tone Plate and Process

Compatible with Present Military Lithographic

Reproduction Equipment and Practices

Advanced Digital Radar Imagery Exploitation

Robust System (ADRIES) Annual Report

Advanced Digital Radar Imagery Exploitation

System (ADRIES) Final Report (1986-1990)

Advanced Edit System

Advanced Development Prototype (ADP) for the

Quick Response Multicolor Printer (QRMP)

Advanced Feature Symbolization for ThreeDimensional Views

Advanced Methods for the Calibration of Metric Cameras

Advanced Radar Topographic Application

Advanced Satellite Hardware/Software System Study Advanced Satellite Tracking Instrumentation Study

Advanced Study of a Position and Azimuth Determining System (Final)

Advanced Study of a Position and Azimuth Determining System (Addendum)

Advanced Study of a Position and Azimuth

Determining System (Supplement)

Advanced Techniques for the Reduction of Geodetic SECOR Observation (Final)

Advanced Techniques for the Reduction of Geodetic SECOR Observation (Supplement)

Aerial Triangulation by Least Squares, Final Report AGFA Contour Film

Airborne Positioning and Attitude Data Application Study, Phase I

Airborne Positioning and Attitude Data

Applications Study, Phase II

$\begin{array}{ll}\text { ETL-0256 } & 1981 \\ \text { ETL-0217 } & 1980 \\ \text { ETL-0218 } & 1980 \\ \text { ETL-0577 } & 1990 \\ \text { ETL-0056 } & 1975 \\ & \\ \text { ETL-0578 } & 1990 \\ \text { ETL-0579 } & 1990 \\ \text { ETL-0295 } & 1983 \\ \text { ETL-0392 } & 1987 \\ \text { ETL-0223 } & 1980\end{array}$

AD $706870 \quad 1968$

ETL-CR-73-2 1973

ETL-0225 $\quad 1980$

AD $8822546 \quad 1968$

AD 844 930L $\quad 1968$

AD 848 369L $\quad 1968$

AD 861 446L 1969

AD $640238 \quad 1966$

AD $664744 \quad 1967$

AD $140062 \quad 1957$

ETL-TR-73-1 1973

AD 815 525L $\quad 1967$

AD 815 526L 1967 
Air Photo Analysis, Photo Interpretation Logic,

ETL-0329

and Feature Extraction

Algorithms for Digital Terrain Data Modeling

ETL-0302 1982

All-Weather Mapping Contour Plotting Program

Alternative Theories of Inference in Expert

ETL-0382

1985

Systems for Image Analysis

Altimeter, Surveying, 4500 Meters, 2-Meter

1350-TR

1954 Divisions

Analog Graphic Processing for 3-D Terrain

ETL-0026

1975

Displays, Profiles, and Elevation Layer Tints

Analog to Digital Converter to Digital Magnetic

Recorder Interface

Analysis and Development of Digital Mapping System Software

Analysis and Development of Image Statistics and Redundancy Removal

Analysis and Simulation of Discrete Digital Image Matching

ETL-CR-71-4

1971

ETL-CR-74-5

1974

ETL-0239

1980

ETL-0278

1981

Analysis and Test Results of a Gyrocompass

With Reduced Susceptibility to Shock,

Vibration, and Motion

ETL-0501

1988

ETL-0378

1984 Gyrocompassing Accuracy

Analysis of Air Photo and Radar Imagery of Barro Colorado Island, Panama, An

Analysis of a Relaxation Scheme to Improve Terrain

ETL-0540

1989

ETL-0298

1982

Elevation Data, An

Analysis of Edge Detection Algorithms on DIAL

Analysis of GEOS PC-1000 and SECOR Data

Analysis of Interactive Image Cleansing Via Raster-Processing Techniques

Analysis of LANDSAT Systems for Cartographic and

ETL-0371

1985

AD $882165 \mathrm{~L} \quad 1967$

ETL-0347

1983

ETL-0103

1977

Terrain Information (Report No. 9 in the ETL Series on Remote Sensing)

Analysis of Multispectral Scanner Data for Location of Sand and Gravel Deposits

Analysis of Radar Calibration Data (Final)

Analysis of Radar Calibration Data (Supplement)

Analysis of SECOR Data - Vol. I

Analysis of SECOR Data - Vol. II

Analysis of the Max-Min Texture Measure, An

Analysis, Storage and Retrieval of Elevation

Data with Applications to Improve Penetration

Analytic Aerotriangulation: Triplets and Sub-Blocks

Including Use of Auxiliary Data

Analytical Aerial Triangulation

AD 705673

1970

AD $827858 \mathrm{~L}$

1967

AD 836 943L

1968

AD 865 488L

1968

AD $865489 \mathrm{~L}$

1969

ETL-0280

1982

ETL-0179

1979

AD 631072

1965

1510-TR

1958 
Analytical Aerial Triangulation Error Analysis

AD 271442

1961

and Application of Compensating Equations to

the General Block Triangulation and Adjustment

Program (Interim)

Analytical Aerial Triangulation Error Analysis

AD 401-689

1962

and Application of Compensating Equations to

the General Block Triangulation and Adjustment

Program (Final)

Analytical Aerial Triangulation with Large

Computer (Analytical Simultaneous Block

Triangulation Technique)

Analytical Aerial Triangulation with Small Computer

Analytical Aerotriangulation Using Triplets in Strips

Analytical Photogrammetric Position System (APPS)

Analytical Photogrammetric Position System (APPS)

to Support the Field Army

Apparent Temperature and Emissivity of Natural

Surfaces at Microwave Frequencies

34-TR

1966

13-TR

1963

AD 668683

1965

ETL-TR-74-2

1973

ETL-TR-74-4

1974

AD $872878 \mathrm{~L}$

1970

Appendix III Narrative Report for Geoscience

Overlays

Application of a Feature Selection Technique to

Samples of High Resolution Synthetic Aperture

Radar Imagery

Application of a Phase Comparison Radiolocation

System to Distance and Position Measurement over Mountainous and Desert Terrain

Application of Artificial Intelligence to Radar

Image Understanding

Application of Biorthogonal Filter Functions to

Pattern Recognition and Feature Extraction

Application of Coriolis Force to Geodetic

Measurements

Application of Hierarchical Data Structures to

Geographical Information Systems

Application of Hierarchical Data Structures to

Geographical Information Systems (Phase II)

Application of Hierarchical Data Structures to

Geographical Information Systems (Phase III)

Application of Hierarchical Data Structures to

Geographical Information Systems (Phase IV)

Application of Inertial Techniques to Surveying

Application of Image Sensing Arrays to Metrology,

Detection and Instrumentation

Application of Image Sensing Arrays to Metrology,

Detection and Instrumentation

ETL-0387

1985

ETL-0222

1980

AD $477136 \quad 1965$

ETL-0301

1982

ETL-0337

1983

ETL-0376 $\quad 1984$

ETL-0411 $\quad 1985$

AD $805156 \quad 1966$

ETL-CR-71-6 1970

ETL-CR-72-5 1972 
Application of Image Sensing Arrays to Metrology,

ETL-CR-74-9

Detection and Mapping, Interim

Application of LORAC to Precision Terrestrial Line-

AD 232015

no date

Length Measurement and Position Fixing

Application of Scalar Renormalization to the

ETL-0020

1975

Scattering of Electromagnetic Waves from a

Three-Dimensionally Inhomogeneous Medium with

Strong Dielectric Fluctuations

Applications of Advanced Accelerometers to

AD $429324 \mathrm{~L}$

1963

Surveying and Geodesy I

Applications of Advanced Accelerometers to

AD 439 969L

1964

Surveying and Geodesy II

Applying Photogrammetry to Real Time Collection

ETL-0275

1981

of Digital Image Data

Approach to Model Formation Based on Formal

Geometric Reasoning, An

ETL-0493

1988

Approach to the Evaluation of Strategies in

AD 722787

1968

Insurgency, An

APPS-IV Civil Works Data Extraction/Data Base Application Study (Phase I)

APPS-IV Civil Works Data Extraction/Data Base

Application Study (Phase II)

APPS-IV Remote Sensing Applications Guide

ARK-1 Gyro Aiming Circle (Wild Heerbrugg Instruments, Inc.)

ARMIDOP/ZERO-DOP Positioning Technique

Army Tactical Terrain Data Requirements Forecast (FY87-FY93)

Army Terrain Information System

ARPA Unmanned Ground Vehicle Stereo Vision Program

at Teleos Research: Annual Report

ETL-0310

1982

ETL-0336

1983

ETL-0333

1983

49-TR

1969

ETL-RN-71-2

1971

ETL-SR-1

1987

ETL-0050

1976

TEC-0034

1993

ARPA Unmanned Ground Vehicle Stereo Vision Program

TEC-0052

1994

Artifact Removal in Frequency Domain Compressed Imagery

Artillery Survey System, Phase 1 - Study of Methods

Aspects and Methods of Nonisotropic Land

ETL-0233

1980

AD $883288 \mathrm{~L} \quad 1958$

ETL-RN-71-4

1971

Navigation Error Control Including

Consideration of Topography

Assessment of Inertial Technology for Gravity

ETL-0291-1

1982

Survey Applications

Assessment of Means for Determining Deflection

ETL-0303

1982 of the Vertical

Assistant for Science and Technology Analyst (ASTA)

Associative Array Processing of Raster Scanned

Data for Automated Cartography

ETL-0570

1990

ETL-0046

1976 


\section{TITLE}

Associative Array Processing of Raster Scanned

Data for Automated Cartography II (Improved

Resolution and Data Handling)

Associative Array Processing for Topographic

Data Reduction

Associative Array Processing for Topographic

Data Reduction, Final Report

Astrogeodetic-Inertial Methods for Vertical

Deflection Determination

Astronomical Attachment Azimuth Determination,

Reflecting, for Transit or Theodolite

ATF-Hadego Photocompositor Photolettering Machine

Atmospheric Refraction

Atmospheric Refraction for Satellite Photography

Autocorrelation of Control Points on 11-Band

Multispectral Imagery

Autonomous Land Vehicle (ALV) Program - Seventh

Quarterly Report, The

Approach to Model Formation Based on

Formal Geometric Reasoning, Second

Annual Report, An

Automated Classification of Basic-Level Terrain

Features in Digital Elevation Models

Automated Extraction of Airport Runway Patterns

From Radar Imagery

Automated Feature Attribute Accessing From

Map Text

Automated Industrial Feature Extraction from

Synthetic Aperture Radar Imagery

Automated Processing of Geographic Information

in Image Data Forms

Automated Route Finder for Multiple Tank Columns

Automated SAR Change Detection for Combat Support

Phase I

Automated Segmentation and Extraction of Area

Terrain Features From Radar Imagery

Automated Software System for Updating Digital

Terrain Databases From All-Source Imagery,

Phase I SBIR

Automated Technique for Measuring Built-Up Urban

Areas from Map Graphics through Analog Image

Processing

Automatic Contour Digitizer (ACD)

Automatic Contouring Instrumentation
REPORT NO.

YEAR

ETL-0132

1977

ETL-CR-74-1

1974

ETL-CR-74-20

1974

ETL-0414

1985

1374-TR

1954

1414-TR

TR-61-505

$56-8 \mathrm{~B}-1$

(955

ETL-0473

1962

1987

ETL-0496

1988

ETL-0527

1989

TEC-0013

1992

ETL-0567

1990

ETL-0517

1988

ETL-0459

1987

ETL-0114

1977

ETL-0480

1987

ETL-0574

1990

ETL-0554

1990

ETL-0584

1991

ETL-0012

1975

ETL-ETR-71-2

1971

1488-TR 


\section{TITLE}

Automatic Control of Digital Stereo Correlation Methods

Automatic Correlation of USGS Digital Line Graph

Geographic Features to GNIS Names Data

Automatic-electro Optical Satellite Triangulation System

Automatic Feature Extraction/Algorithm Testing

Automatic Feature Extraction: An Annotated

Bibliography

Automatic Line Network Extraction From Aerial

Imagery of Urban Areas Through Knowledge

Based Image Analysis

Automatic Map Compilation System

Automatic Point Marking Measuring and Recording Instrument

Automatic Point Transfer Instrument

Automatic Reseau Measuring Equipment (ARME)

Automatic Stereo Perception of Aerial

Photography by Means of Optical Correlation

Automatic Radar Feature Extraction System

Using Descriptors

Automatic Type/Symbol-Placement Developments

Automation of Airborne Profile Recorder Data

Reduction (Interim)

Automation of Airborne Profile Recorder Data

Reduction (Final)

Autonomous Ground Vehicles: Control System

Technology Development

Autonomous Land Vehicle

Autonomous Land Vehicle (ALV) Planning and

Navigation System

Autonomous Land Vehicle (ALV) Program Phase II -

First Quarterly Scientific and Technical Report, The

Autonomous Land Vehicle (ALV) Program Phase II -

Second Quarterly Scientific and Technical Report, The

Autonomous Land Vehicle 1st Quarterly Report, The

Autonomous Land Vehicle 2nd Quarterly Report, The

Autonomous Land Vehicle (ALV) Program, Third

Quarterly Report, The

Autonomous Land Vèhicle (ALV) Program, Fourth

Quarterly Report, The

Autonomous Land Vehicle (ALV) Program, Fifth

Quarterly Report, The

Autonomous Land Vehicle (ALV) Program,

Sixth Quarterly Report, The
REPORT NO.

YEAR

ETL-0356

1984

ETL-0426

1986

$\mathrm{RN}-23$

1967

ETL-0410

1985

ETL-0189

1979

ETL-0568

1989

AD 277456

1962

AD 610044

1964

AD $834230 \mathrm{~L} \quad 1968$

ETL-0099

1976

AD 406363

1962

ETL-0533

1989

ETL-TR-74-9

1975

AD 805 562L

1966

AD $825545 \mathrm{~L}$

1967

ETL-0375

1984

ETL-0413

1986

ETL-0465

1987

ETL-0515

1988

ETL-0526

1988

ETL-0430

1986

ETL-0436

1986

ETL-0450

1986

ETL-0460

1987

ETL-0468

1987

ETL-0483

1987 
TITLE

Autonomous Land Vehicle (ALV) Program, Seventh

Quarterly Report, The

Autonomous Land Vehicle (ALV) Program

Phase I, Final Report

Autonomous Land Vehicle (ALV) Planning and

Navigation, Second Annual Report

Autonomous Land Vehicle (ALV) Planning and

Navigation System, Final Annual Report

Background Study and Selection Criteria

Analysis of MIL-STD-810C: Environmental

Test Methods

Backscattering of Electromagnetic Waves from

a Slightly Rough Surface with a Lossy Layer

Backscattering of Electromagnetic Waves from

a Surface Composed of Two Types of Surface

Roughness

Backscattering of Radar Waves by Vegetated

Terrain

Backscattering of Radar Waves from a Tilted, Slightly Rough Surface

Base Plant Correlator

Base Plant Correlator (Final)

Basic Factors Limiting the Accuracy of Mapping

and Aerotriangulation by Photogrammetric

Procedures

Battlefield Assessment and Decision Assistance

System Using Neural Networks and an Expert

System Director

Bayesian Approach to Identification of a

Remotely Sensed Environment

Bibliographic Literature Search Concerning the Relationship Between Soils and Plants in Arid and Semi-Arid Regions in North America

Bibliography and Abstracts of Analytical Photogrammetry

Bibliography of In-House and Contract Reports

Bibliography of In-House and Contract Reports, Supplement 1

Bibliography of In-House and Contract Reports, Supplement 2

Bibliography of In-House and Contract Reports, Supplement 3

Bibliography of In-House and Contract Reports, Supplement 4
REPORT NO.

YEAR

ETL-0496

1988

ETL-0506

1988

ETL-0511

1988

ETL-0539

1989

ETL-0154

1978

ETL-TR-74-10

1974

ETL-TR-71-4

1971

ETL-0105

1977

ETL-0124

1977

ETL-CR-71-15

1971

ETL-CR-73-3

1973

AD 77390

1955

TEC-0002

1992

AD 860060

1969

ETL-0171

1978

1487-TR

1957

ETL-SR-70-1

1970

ETL-SR-71-3

1971

ETL-SR-72-3

1972

ETL-0013

1975

ETL-0042

1976 


\section{TITLE}

Bibliography of In-House and Contract Reports, Supplement 5

Bibliography of In-House and Contract Reports, Supplement 6

Bibliography of In-House and Contract Reports, Supplement 7

Bibliography of In-House and Contract Reports, Supplement 8

Bibliography of In-House and Contract Reports, Supplement 9

Bibliography of In-House and Contract Reports, Supplement 10

Bibliography of In-House and Contract Reports, Supplement 11

Bibliography of In-House and Contract Reports, Supplement 12

Bibliography of In-House and Contract Reports, Supplement 13

Bibliography of In-House and Contract Reports, Supplement 14

Bibliography of In-House and Contract Reports, Supplement 15

Bibliography of In-House and Contract Reports, Supplement 16

Bibliography of In-House and Contract Reports, Supplement 17

Bibliography on the Chemical Weathering of Granitic Rocks, A

Bimodal Display

Blue Laser

Brigade Level Hard Copy Device

Broad-Spectrum Electromagnetic Spectrum Backscatter

Brush Surfaced Lithographic Press Plates

Building a 3-D World Model for a Mobile Robot from Sensory Data

Built-Up Area Feature Extraction: First Year Report

Built-Up Area Feature Extraction: Second Year Technical Progress Report

Built-Up Area Feature Extraction: Final Report

Camera Calibration Study

Capabilities of Remote Sensors to Determine

Environmental Information for Combat

Cartographic Application of Conflex I
REPORT NO.

YEAR

ETL-0104

1977

ETL-0143

1978

ETL-0180

1979

ETL-0216

1980

ETL-0255

1981

ETL-0282

1982

ETL-0320

1983

ETL-0353

1984

ETL-0395

1985

ETL-0434

1986

ETL-0500

1988

ETL-0550

1989

ETL-0575

1991

ETL-0505

1988

ETL-0110

197

ETL-0412

1985

TEC-0019

1991

AD 878 341L

1970

1452-TR

1956

ETL-0490

1988

ETL-0561

1990

ETL-0562

1990

TEC-0016

1991

ETL-0081

no date

1976

AD 882789 L

1964 


\section{TITLE}

Cartographic Design Standards - A Preliminary Investigation

Cartographic Drafting Methods and Equipment

Cartographic Drafting Methods and Equipment

(Plastic Scribing Process)

Second Interim Report

Cartographic Electron Beam Recorder (EBR) System

Cartographic Electron Beam Scanner Design Study

Cartographic Scanner Plotter

Change Detector Maintenance Instructions

Change Detector Operation Manual

Change Detector Studies

Characterization and Optimization of an

Electro-Optic Imaging Device for Real-Time

Map Profiling

Characterization of the PROM for Coherent

Optical Processing Applications

Charging Equipment, Mobile (CEM)

Chemical Array Studies

Circularly Polarized Measurements of Radar

Backscatter from Terrain

Circularly Polarized Measurements of Radar

Backscatter from Terrain and Snow Covered

Terrain

Circumpolar Method for Determining Azimuth

Classification and World Distribution of

Vegetation Relative to V/STOL Aircraft

Operations

Classification of Cartographic Features

Through Walsh Transforms

Classification of Metamorphic Rocks and

Their Applications to Air Photo

Interpretation Procedures, The

Classification of Selected Radar Imagery

Patterns Using a Binary Tree Classifier

Climatic Information for Application in Designing and Testing U.S. Army Materiel

CMU (Carnegie-Mellon University) Strategic Computing Vision Project Report: 1984 to 1985

Coated Paper and Developer for Continuous

Tone Electrophotography

Cold Weather Testing of 10-Second Direction

Theodolite, 1-Minute Direction Theodolite

(Foreign Model), Astronomical Attachment, and Winterization Kit

Color Contact Printer Mark III
REPORT NO.

YEAR

1967

1305-TR

1953

1339-TR

1954

ETL-0111

1977

ETL-0257

1981

ETL-CR-72-12

1972

1966

1965

1961

ETL-CR-74-18

1974

ETL-0053

1976

ETL-0089

1976

ETL-0130

1977

ETL-0199

1980

ETL-0234

1980

ETL-0317

1983

ETL-SR-74-4

1973

ETL-0290

1982

ETL-0341

1983

ETL-0442

1986

ETL-0474

1987

ETL-0466

1987

AD $674241 \quad 1968$

1288-TR

1953

ETL-ETR-70-9

1970 


\section{TITLE}

Color Ink-Jet Demonstration Program

Color Orthophotomaps

Color Separation System Evaluation

Combination Map Reproduction Van Body

Combined Engineering and Service Tests of the

Copy and Supply Van Section of the Motorized

Photomapping Train

Combined Engineering and Service Tests of the

Map Revision Van Section of the Motorized

Photomapping Train

Combined Engineering and Service Tests of the

Multiplex Van Section of the Motorized

Photomapping Train

Combined Engineering and Service Tests of the

Photomapping Van Section of the Motorized

Photomapping Train

Combined Engineering and Service Tests of the

Rectifier Van Section of the Motorized

Photomapping Train

Command Retrieval Information System/Direct Input (CRIS/DI)

Comparative Aerotriangulation Tests of the Multiplex Kelsh Plotter, Stereoplanigraph, Wild Autograph Model A-5, and Wild Stereoplotter Model A-6

Comparative Study of Photography for Soils and Terrain Data

Comparison of Air Photo Landform Units to Statistically Defined Groups of Tors in Dartmoor, Southwest England

Comparison of Air Photo Lineations and Joint Patterns, Dartmoor, Southwest England

Comparison of Soils from Twentynine Palms, CA and Saudi Arabia, A

Comprehensive Summary of Project Trend

Computer-Assisted Likely Minesite Prediction

Model and Estimated Electromagnetic and

Thermal Soil Properties

Computer for Army Artillery Inertial Survey System (GEISHA)

Computer Generation of Fractal Terrains

Computer Program to Simulate Scenario Functions

Computer Strategy for Detecting Line Features

on Simulated Binary Arrays in Support of Radar

Feature Extraction

Computing a Line-of-Sight Using Digital Image

Matching and Analytical Photogrammetry
REPORT NO.

YEAR

ETL-0196

1979

ETL-ETR-72-2 1972

AD $672078 \quad 1968$

1536-TR

1958

1444-TR

1956

1447-TR

1956

1520-TR

1958

1428-TR

1955

1544-TR

1958

42-TR

1968

1349-TR

1954

38-TR

1968

TEC-0001

1992

TEC-0006

1992

ETL-0583

1991

ETL-0041

1975

ETL-0391

1985

AD 814052

1963

ETL-0504

1988

ETL-0025

1975

ETL-0478

1988

ETL-0027

1975 


\section{TITLE}

Consensus Theory in Expert Systems: An Adaptive Inference Framework and Application to Image Understanding

Concept Development of Automated Image Analysis

Concept Development of Automatic Instrumentation for Monitoring Movement of Dams

Concept for an Ultraprecise Geodetic Baseline

Conifer Tree Influence on Digital Terrain Elevation Data (DTED): A Case Study at Dulles International Airport

CONPLOT I - A Contour Generating Program

CONPLOT II - A Contour Generating Program

CONRAD - A Program to Contour Radar Data

Continuous-Tone Electrophotography

Contour Digitizing and Tagging Software (CONTAGRID)

Contour-to-Grid Interpolation with Nonlinear Finite Elements: A Feasibility Study

Contribution to the Philosophy of Climatic Design Limits for Army Materiel: Extreme Hot-Desert Conditions

Control Unit for Army Artillery Inertial Survey System (GEISHA)

Controlled Color for Contact Printing Aerial Imagery

Conversion of the CALAP Program from FORTRAN to DUCK. Final Report

Cooperative Autonomous Agents Testbed - First Annual Report

Cooperative Autonomous Agents Testbed - Second Annual Report

Coordinate Measurement Research: Basic and Applied Experiments with the NegativeReticle Concept

Corona Study Relevant to Electrostatic Printing Process

Corps of Engineers Maintenance Package for Inertial Survey Equipment

Correlation of Noisy Images

Cultural Data Base Implementation Study and Computer-Aided Scene Modeling System Users Manual

Cumulative Probability Tables for Testing Consensus in Ranking Experiments
REPORT NO.

YEAR

ETL-0524

1988

ETL-0194

1979

ETL-0187

1979

RN-24

1967

TEC-0038

1993

ETL-CR-70-2 1970

ETL-CR-71-1 1971

ETL-CR-73-20 1973

AD $673881 \quad 1968$

ETL-0228

1980

ETL-0472

1987

ETL-TR-72-5

1972

AD $814068 \quad 1968$

ETL-TR-72-4

1972

ETL-0419

1986

ETL-0571

1990

TEC-0051

1993

ETL-CR-72-14

1972

ETL-CR-71-22 1971

AD $847498 \quad 1963$

ETL-0230 1980

ETL-0380 1984

ETL-0418

1986 


\section{TITLE}

Data Base Sizing Methodology Applied to the Army Terrain Information System (ARTINS)

Data Integrity Factors Affecting the Construction of the Mapping, Charting, and Geodesy Data Base

Data Weighing Analysis

Decision Path Approach to Guidance for Climatic Environmental Test Planning (MIL-STD-810C)

Defense Mapping Agency Advanced Raster-to-Vector Benchmark Testing

Defense Mapping Agency (DMA) Raster-to-Vector Analysis

Defense Mapping Agency (DMA) Raster-to-Vector Analysis - Appendix

Defense Mapping Agency (DMA) Raster-to-Vector Benchmark Testing

Delta Pulse Code Modulation Compression Relative to Stereo Image Matching

Demonstration and Evaluation of the Utilization of Side-Looking Airborne Radar for Military Terrain Analysis

Derivation and Potential of New Filter Equations for Numerical Weather Prediction

Description of Instrumentation Data Analysis and Reduction for an Atmospheric Seeing Monitor

Design and Analysis of a High-Production MiniComputer System for Regridding Digital Terrain Elevation Matrices

Design and Development of a Position and Azimuth Determining System (PADS)

Design and Development of an Advanced Electron Beam Control System

Design and Development of Power Package for Surveying Instrument: Azimuth, Gyro, Lightweight

Design and Development of Surveying Instrument: Azimuth, Gyro, Lightweight (SIAGL)

Design and Fabrication of a 70 Millimeter Interference Imaging System

Design and Fabrication of an Experimental Multiband Camera

Design and Feasibility Study of an Off-Line Digital Orthoprinter for Field Use Design and Feasibility Study of HOC as a Van Mounted Stereo Model Digitizer
REPORT NO.

YEAR

ETL-0150

1978

ETL-0357

1983

AD 672101

1968

ETL-0183

1979

ETL-0420

1986

ETL-0383

1984

ETL-0383A

1984

ETL-0384

1984

ETL-0157

1978

ETL-0023

1975

ETL-RN-71-3

1971

AD 701124

1969

ETL-0240

1980

ETL-CR-71-18

1971

ETL-0032

1975

ETL-CR-71-5A

1971

ETL-CR-71-5

1971

ETL-CR-71-8

1971

ETL-CR-71-28

1971

ETL-0149

1978

ETL-0109

1977 


\section{TITLE}

Design, Fabrication, and Test of a Position and Azimuth Determining System (PADS)

Design Issues in Video Disc Map Display

Design, Modification, Fabrication, and Test of a Prototype Miniaturized North Reference Unit (MINRU)

Design of a Laser Experiment for the Verification of the Inverse Scattering Theory

Design of a Map Update Capability for Engineer Topographic Units

Design of an Experimental Program for Evaluation of LBR Systems

Design of Engineering Test Model, Topographic Data System

Volume 1

Volume 2

Volume 3

Volume 4

Volume 5

Design Studies and Prototype Model Development of a Small North Orienting Device (Miniaturized Gyrocompass)

Design Study of a Large Format Printer (LFP)

Desk Model Fotosetter Photo-Lettering Machine

Detecting Line-Road and Road-Intersection Patterns at Various Angles

Determination of Height Differences from Gravity and Gravity Gradients

Determination of Level Sensitivity (Field Calibration with the Level on the Instrument)

Determination of the Anomalous Gravity Potential from Satellite and Terrestrial Data Under Utilization of Modern Gravimetric Theory

Determination of the Geometrical Quality of Comparators for Image Coordinate Measurements

Determinations and Statistical Studies of Gravimetric Deflections

Determinations and Statistical Studies of Gravimetric Deflections, Final Report

Determinations of Direct and Inverse Azimuths, Zenith Distance, Hour Angle, Declination and Distance Between Two Points on Normal Sections

Determining an Azimuth with a Gyrotheodolite
REPORT NO.

YEAR

ETL-CR-73-6

1973

ETL-0362

1984

ETL-0276

1979

AD $463012 \mathrm{~L}$

1965

ETL-0107

1977

ETL-0182

1979

AD 270 216L

1961

AD 270 205L

1961

AD $270207 \mathrm{~L}$

1961

AD 270 210L

1961

AD 270 209L

1961

ETL-CR-70-4

1970

ETL-0368

1984

1329-TR

1953

ETL-0274

1981

ETL-71-CR-10

1971

ETL-RN-74-4

1974

ETL-RN-73-2

1973

RN-3

1962

ETL-CR-74-8

1973

ETL-0017

1975

RN-19

1967

ETL-0440

1986 
Determining the Translation of a Rigidly Moving

ETL-0475

Surface, Without Correspondence

Developing a Data Base for Predicting

ETL-0015

1975

Soviet Tactical Behavior

Development of a High Precision Capability for

ETL-0121

1977

Monitoring Structural Movements of Locks and Dams

Development of an Integrated Mobile Robot System

ETL-0546

1989

at Carnegie Mellon University

Development of an Integrated Mobile Robot System at Carnegie Mellon University

Development of a Prototype Family of Military Geographic Intelligence Products to Support Airmobile Operations

Development of a Small North Orienting Device

Development of a Statistical Method for Three Dimensional Terrain Elevation Error Analysis

Development of a Terrain Profile Recorder Image Point Transfer Instrument

Development of Automatic Names Placement Software

Development of a Variscale Stereo Point Marking Instrument

ETL-0565

1990

ETL-ETR-70-7

1970

AD 869 896L

1970

TEC-0030

1991

AD 649830

1967

ETL-0484

1987

AD 643722

1966

Development of an Evaluation Model-Change

1965

Detector

Development of an Experimental Family of Military Geographic Intelligence (MGI)

ETL-TR-72-3

1972 Products to Support Battlefield Sensor Activities

Development of an Integrated Mobile Robot System

ETL-0565

1990 at Carnegie Mellon University

Development of an Integrated Mobile Robot System at Carnegie Mellon University

Development of an Integrated Mobile Robot System at CMU, June 1987 Annual Report

Development of Computer Vision Techniques for Automatic Feature Extraction

ETL-0546

1989

ETL-0508

1988

ETL-0451

1987

Development of Descriptor Sets for the

ETL-0369

1984 Unambiguous Characterization of Geographic

Features on SAR Imagery

Development of Electronic Control of a

ETL-0397

1985

Superconducting Gravity Gradiometer

Development of Electronic Control of a Super-

ETL-0447 
Development of Finite Element Models for the

ETL-0096

Earth's Gravity Field Phase I: Macro Gravity

Model for Satellite Orbit Integration

Development of Finite Element Models for the

ETL-0097

1977

Earth's Gravity Field Phase II: Fine

Structure Disturbance Gravity Representations

Development of Height Finder Oblique,

383-TR

1954

Topographic

Development of High Speed CRT Print Head Systems

ETL-0213

1980 for Cartographic Applications

Development of Improved Area Correlation

ETL-CR-73-19

1973 Techniques

Development of Lightweight Long-Range Survey

AD 477042

1965 System (LRSS)

Development of Spherical Map Sections and Transparent Conforming Overlays

Development, Service Tests, and Production Model Tests, Autofocusing Rectifier

Development, Test, Preparation, Delivery, and Installation of Algorithms for Optimal Adjustment of Inertial Survey Data

Developmental Optical Correlator

DFAD PLUS System Development

Digest of High Temperature Storage Literature

Digital Automatic Map Compilation System

Digital Cartographic Study and Benchmark

Digital Cartographic Study and Benchmark First Interim Technical Report

Digital Cartographic Study and Benchmark Second Interim Technical Report

Digital Cartographic Study and Benchmark Third Interim Technical Report

Digital Cartographic Study and Benchmark Fourth Interim Technical Report

Digital Computer Program for the Solution of a Photogrammetric Net (Preparation of Maps from Aerial Photographs)

Digital Data Editing System

440-TR

1956

1307-TR

1953

ETL-1307

1982

ETL-0033

1975

TEC-0031

1992

ETL-0152

1978

AD $285258 \quad 1962$

ETL-0168

1978

ETL-0090

1975

ETL-0091

1975

ETL-0092

1976

ETL-0093

1977

AD 711858

1961

Digital Data to Pressplate Study

Digital Image Manipulation and Enhancement System (DIMES) User's Handbook

Digital Laser Platemaker Modifications

ETL-0146

1977

ETL-0044

1976

ETL-CR-73-7

1973

Digital Map Color Proofing Methodologies

Evaluation, Final Report

ETL-0379

1984

ETL-0372

1984 


\section{TITLE}

Digital Map Color Proofing Methodologies

Evaluation, Final Report (Proprietary)

Digital Mapping Glossary

Digital Mapping System Concepts Study

Digital Mapping System: Mathematical Processing

Digital Mapping System Study

Digital Multicolor Recorders and Scanner

The Technology and the Equipment

Digital Planimetric Compiler

Digital Pre-Press System Design Study

Digital Radar Restitution

Digital Rectification of Side-Looking Radar

(DRESLR)

Digital Simulation of a Radar Image of Pisgah

Crater Test Site, California

Digital Terrain Analysis Module (DTAM)

Digital Terrain Data Compaction Using Array Algebra

Digital Terrain Elevation Data (DTED) Resolution and Requirements Study: Phase 2 Report

Digital Terrain Elevation Data Resolution and

Requirements Study - Interim Report

Digital Terrain Elevation Model Analysis

Dimensionally Stable Opaque Cartographic Bases

Direct Digital Color Proofing Technology Overview

Direct Electronic Transforms for Feature Extraction

Discrete Scattering Approach to Vegetation Modeling

Discrimination of Tropical Land Use in Puerto

Rico: An Analysis Using Multispectral Imagery

Discrimination of Water from Shadow Regions on

Radar Imagery Using Computer Vision Techniques

Display Technologies for Topographic Applications.

Assessment of State-of-the-Art and Forecast

Distribution of Mean Monthly Precipitation and

Rainfall Intensities

Diurnal Freeze-Thaw Frequencies in Selected

Regions of the High Latitudes

Domain-Dependent Reasoning for Visual Navigation of Roadways

Doppler Satellite for Army Field Operations

Doppler Translocation Test Program

Doppler Translocation Test Program

Dynamic Image Interpretation for Autonomous

Vehicle Navigation
REPORT NO.

ETL-0373

1984

AD A782 328

1974

ETL-CR-71-26

1971

ETL-CR-74-6

1974

ETL-CR-71-25

1971

ETL-0551

1989

ETL-ETR-72-1

1972

ETL-0339

1983

AD 448 230L

1964

ETL-CR-73-18

1973

ETL-0019

1975

TEC-0018

1991

ETL-0108

1976

TEC-0035

1993

ETL-SR-6

1990

ETL-0393

1985

1469-TR

1956

ETL-0351

1984

ETL-0139

1978

ETL-0215

1980

ETL-CR-71-20

1971

ETL-0404

1985

ETL-0016

1975

ETL-SR-72-5

1972

ETL-0364

1984

ETL-0445

1986

AD 470472

1965

41-TR

1968

ETL-ETR-74-5

1974

ETL-0437 
Vehicle Navigation, 1987 End of Year Technical Report

Dynamic Image Interpretation for Autonomous

ETL-0549

1989

Vehicle Navigation - Final Report

Earth's Gravitational Field from Observation

RN-30

1968

of Near-Earth Satellites and Terrestrial

Gravity Measurements

EBR Extension of Graphics Generator to

Include Symbols

Edge Detection Experiment Using the MARR Operator, An

Effects of Soil Moisture and Vegetation on Surface Temperature, The

Effects of Supersonic and Hypersonic Aircraft Speed upon Aerial Photography

Effects of Supersonic and Hypersonic Aircraft Speed upon Aerial Photography

Effects of Supersonic and Hypersonic Aircraft Speed upon Aerial Photography, Final Report

Effects of the Atmosphere on Aerial Photography

Electrofax Specifications for Army Five-Color

Map Reproducing Equipment

Electron Beam Recorder Applications Study

Electronic Angle-Measuring Device

TL-CR-74-12

1974

ETL-0435

1986

ETL-0324

1983

Electronic Feedback Control of Mass-Spring Systems

AD 226577

1959

AD 248726

1960

Electronic Pointing Device (Microwave) System

(Electrotransit)

Electronic Printing Systems

Electronic Survey Equipment and Tests

Electro-Optical Image Processing with an Image

Storage Tube

Electrophotographic Imaging Materials Evaluation

Electrostatic Paper and Toner Development

Elevation Data Compaction by Polynomial Modeling

Elevation Data Edit Terminal

Empirical Surface Temperature Model, An

Emergency Target Location Function

End of Year Report for Parallel Vision Algorithm

Design and Implementation

End of Year Technical Report: Dynamic Image Interpretation for Autonomous Vehicle Navigation

Engineer Design Test and Evaluation of a

Planimetric Compiler

TN-70-1

1970

AD $841828 \mathrm{~L} \quad 1968$

ETL-0120

1970

ETL-TR-72-1 1972

ETL-0398

1985

AD $471726 \mathrm{~L} \quad 1965$

ETL-0423

1986

AD-264 454

1960

AD A836 685

1968

ETL-0266

1981

1969

ETL-0140 1978

ETL-0328 1983

ETL-0503 1988

21-TR

1965

ETL-0467

1987

ETL-0463

1987

35-TR

1966 
Retrieval Information System/Direct Input (CRIS/DI)

Engineer Tests of 2.5x Reduction Printer

ETL-ETR-74-7

1975

Engineering Design Test Report: Inertial

16-TR

1963

Surveying Equipment (ISE)

Engineering Evaluation of Pulsed Xenon Light

2-TR

1961

Sources for Graphic Arts Use

Engineering Test Report: Elevation Meter, Ground

Engineering Test Report: Lightweight Gyro

-TR

1962

Azimuth Theodolite (Lear North-Seeking Gyro

11-TR

1963

Model No. 11NG530A)

Engineering Test Report of the Integrated Mapping System

7-TR

1962

Engineering Test Report Short Range Electronic

Positioning Equipment (SREPE)

Engineering Tests and Evaluation of a 9 by 18 inch Electronic Printer

Engineering Tests and Evaluation of Multiplex

Reduction Printer for Metrogon and

Distortion-Free Photography

Engineering Tests and Evaluation of Printers

for the Preparation of $91 / 2$ - by $91 / 2$-inch

Diapositives for the Precision Stereoplotter

Engineering Tests and Evaluation of the Photogrammetric Transforming Printer for $20^{\circ}$

Convergent Photograph

Engineering Tests of a Temperature-controlled

Processing Unit, Deep-tank, for

Photomechanical Film

Engineering Tests of Diapositive Processing Unit

Engineering Tests of Interim Target Location

Systems for Use in Controlled Areas

Engineering Tests of Interim Target-Location

Systems for Use in Uncontrolled Areas

Engineering Tests of Opaque Cartographic Bases

Engineering Tests of Scanning Stereoscope

Engineering Tests of the Cartographic Grid Ruler

Engineering Tests of the Cartographic Van Section of the Motorized Photomapping Train

Engineering Tests of the PPI Radar

9-TR

1963

1646-TR

1960

1431-TR

1955

1538-TR

1958

1497-TR

1957

1599-TR

1959

1628-TR

1960

1498-TR

1957

1612-TR

1960

1290-TR

1953

1491-TR

1957

1486-TR

1957

1373-TR

1954

1629-TR

1960

Presentation Restitutor 


\section{TITLE}

Engineering Tests of Translucent Cartographic Bases

Engineering Tests of Two Printer-Developers, Ammonia Process, 24 Inch

Enhanced Photomap Evaluation Study

Enlarging Printer, 3x

Environmental Conditions Experienced by

Rockets and Missiles in Storage, Transit, and Operations

Environmental Conditions Experienced by Rockets and Missiles in Storage, Transit, and Operations, Supplement

Environmental Conditions in a Tropical Forest Region in Thailand

Environmental Position Errors of the GPS Army User Equipment

Equilibrium Figures and the Normal-spheroid of the Earth Mass-Functions and Isostasy Equipment and Techniques for the Utilization of Convergent Photography in Mapping

Error-Free Compression of Digital Imagery

Error Propagation into Orbital Positions

Error Propagation in Two-Photo Intersection

Error Statistics for Astrogeodetic Positions for an RGSS Test Course

Errors in Automatic Pass Point Mensuration Using Digital Techniques

Establishment of an Ideal World Geodetic System

ETAK Navigator Modification Final Report

ETL 211-OD Gravitational Model, A Union Solution of Optical and Doppler Satellite Determinations

Evaluating Soil Moisture and Textural

Relationships Using Regression Analysis

Evaluation and Comparison of Terrain

Classification Methods (Type III)

Evaluation and Test of a Five-Color

Electrostatic Printing Machine for the

Reproduction of Topographic Maps and Charts

Evaluation and Test of a Modified Plate Process

Section, a Proposed New Photomechanical

Process and a Redesigned Brush-Surfacing Machine

Evaluation and Test of a Self-Contained

Vehicle Land Navigation System
REPORT NO.

YEAR

1461-TR

1956

1292-TR

1953

AD 651396

1967

ETL-0049

1976

ETL-CR-74-3

1973

ETL-CR-74-3-S

1973

ETL-0129

1974

ETL-0055

1976

1968

1583-TR

1959

ETL-0079

1976

ETL-CR-73-13

1973

ETL-RN-72-1

1972

ETL-0267

1981

ETL-0232

1980

AD 680225

1968

ETL-0569

1990

AD 502 044L

1968

ETL-0226

1980

AD $845338 L$

1968

25-TR

1965

1560-TR

1959

ETL-0167

1979 


\section{TITLE}

Evaluation and Test of a Single-Color

Electrostatic Printing Machine for the

Reproduction of Topographic Maps and Charts

Evaluation of a New Electrostatic Recording Medium

Evaluation of a Xerographic Process for

Preparing Zinc Oxide-Silicone, Binder-Type

Lithographic Plates

Evaluation of Automatic Mapping APQ as a

Radar Mapping System

Evaluation of Coherent Radar Photography

Evaluation of Color Recognition Devices for

Making Color-Separations from Multicolor Maps and Charts

Evaluation of Color Test Photography for

Military Geographic Analysis: A Literature

Review

Evaluation of Components for Some

Elevation-Determining Systems

Evaluation of Conventional Correlation Methods

When Matching Infrared Imagery to

Panchromatic Imagery

Evaluation of Experimental Xerographic Process for Lithographic Platemaking

Evaluation of High Precision SHORAN-Controlled Photography

Evaluation of Land Use Techniques for Processing MGI

Evaluation of Multiband and Color Aerial Photography for Selected Military

Geographic Intelligence in a Subtropical

Desert Environment

Evaluation of Offset Collotype Printing for the

Field Reproduction of Aerial Photographs

Evaluation of Pointing to a Sharp Edge

Evaluation of Published Criteria for Identifying

Metamorphic Rocks on Air Photos: Two Case

Studies in the Northeastern-United States

Evaluation of Registering Image Gradients When

Matching Infrared Imagery to Panchromatic

Imagery

Evaluation of Single and Multicolor Map and

Chart Reproduction Equipment

Evaluation of the Bathyscan Sweep Survey System
REPORT NO. YEAR

19-TR

1964

ETL-0102

1977

1545-TR

1958

31-TR

1966

18-TR

1963

1401-TR

1955

ETL-TR-70-6

1970

AD $407297 \mathrm{~L}$

1963

ETL-0195

1979

1417-TR

1955

1484-TR

1957

AD 817 124L

1967

54-TR

1970

1465-TR

1956

AD 668260

1968

ETL-0326

1983

ETL-0250

1981

ETL-0080

1976

ETL-0553

TEC-0008

1992 
Evaluation of the ERDAS Image Processing System and Its Potential Role in the Digital Topographic Support System, An

Evaluation of the Hydrographic Inland Marine

TEC-0012

1992

Acoustic Platform (HI-MAP) Survey System, An

Evaluation of the Method of Determining

ETL-0145

1977

Parallax from Measured Phase Difference

Evaluation of the Prototype, Natural-Image Computer

48-TR

1969

Evaluation of the Stellar-Moon Camera System

Evaluation Tests of Royal Zenith, 29 Press

Evidential Reasoning in Expert Systems for

AD 673270

1968

1490-TR

1957

ETL-0381

1985

Image Analysis

Existing Resources, Standards, and Procedures for

Precise Monitoring and Analysis of Structural

Deformations - Volume I

TEC-0025

1992

Experimental Assessment of Improved Spatial

ETL-0268

1981

Resolution LANDSAT Data

Experimental Correlator Studies

Experimental Determinations of Fringe Counting

Errors Associated with Rotation of a Corner

Cube Forming an Arm of a Laser Interferometer

AD 374 450L

1966

RN-26

1967

Experimental Heterodyne Optical Correlator

ETL-0071

1976

AD 376554

1966

Intelligence Products from Side-Looking

Airborne Radar Imagery

Expert System for Minefield Site Prediction,

ETL-0492

1988

Phase I, First Year Report

Expert System for Minefield Site Prediction,

Phase II, Final Report

Expert System for Minefield Site Prediction,

Phase III, Final Report

Expert System for the Computer-Assisted

Identification of Features on SAR Imagery, An

Expert Vision System for Autonomous Land Vehicle

Road Following, An

Extended Area Exit Pupil Viewer

Extension of Kendall's Concordance Test Where

Ties are Allowed, An

Extraction of Mapping Detail from Radar

Photography

Extraction of Mapping Detail from Radar

Photography

Extreme 24-Hour Snowfalls in the United States:

Accumulation, Distribution, and Frequency

ETL-0534

1989

ETL-0552

1989

ETL-0415

1986

ETL-0489

1988

ETL-0399

1985

ETL-0316

1983

AD 328256

AD 328257

1961

ETL-SR-73-4

1973 
TITLE

Feasibility of a Reduced Power-Consumption Magnetometer for Use in a Digicomp Lensatic Compass

Feasibility of Using Optical Power Spectrum Analysis Techniques for Automatic Feature Classification from High Resolution Thermal, Radar, and Panchromatic Imagery

Feasibility Study for an All-Weather Surveying Signal Light

Feasibility Study for Field Generation of Input for Radar Scene Generation from DLMS Terrain and Elevation Data

Feasibility Study of a Quick Response Multicolor Printer (QRMP)

Feasibility Test of a Proposed 3-D Radar System

Feasibility Test Program for Measurement of Gravity Anomaly Changes Using 2 MICRO-g Accelerometer in the Inertial Platform

Feature Analysis and Reduction of Laws Texture Measure

Feature Component Reduction Through Divergence Analysis

Feature Extraction Assessment Study, Final Report

Feature Extraction of the Illiac IV

Feature Tagging

FEED Evaluation

FEED Software Documentation

Fictitious Data Generator for Analytical Aerotriangulation

Field Artillery Plotting Equipment

Final Report, Development of Mirror Stereoscope

Final Report on Stable Cartographic Bases

Final Report, Study of Digital Matching of Dissimilar Images

Finite Element Models of the Earth's Gravity Field Phase IV

Five-Color Separation Investigation

Fixed and Multiple Frequency Angle Measurements with 35-GHz Microwaves

Floodplain Tree Species: A Bibliographic

Literature Search with Abstracts

Flux Valve Heading Reference System

Forced Dynamics of Asymmetric Spacecraft

Forecast for the 1970's in Mapping, Charting, and Geodesy Research and Development
REPORT NO.

YEAR

ETL-0547

1989

ETL-0186

1979

37-TR

1968

ETL-0203

1978

ETL-0242

1980

AD 349 882L

1964

ETL-CR-74-16

1974

ETL-0343

1983

ETL-0305

1982

ETL-0377

1984

ETL-0191

ETL-0227

1979

1980

ETL-0322

1983

ETL-0335

1983

AD 640799

1965

1421-TR

1955

1382-TR

1954

1542-TR

1958

ETL-0244

1980

ETL-0198

1979

AD 662725

1967

33-TR

1966

ETL-0193

1979

ETL-0134

1977

ETL-0039

1976

TN-70-2 


\section{TITLE}

Formulas for Computing Atmospheric Refraction for Objects Inside or Outside the Atmosphere

Formulation of a Space Oblique Mercator Map Projection

Fort Belvoir Text Placement System, Final Technical Report

Fourier Transform Autocorrelation

Fractures in Rock: An Annotated Bibliography

Frequency Dependence of Backscatter from Rough Surfaces (An Experiment with Broad-Spectrum Acoustic Waves)

Full Color Recorder

Full View Holograms

Further Investigation of an Electronic AngleMeasuring Device

Further Study of Digital Matching of Dissimilar Images

Gamma-Ray Spectrometer Study

GEISHA Computer Theory of Operation

General Climatological Guide to Daily Freezing Conditions: Frost Days, Ice Days, and Freeze-Thaw Days, A

General Noniterative Solution of the Inverse and Direct Geodetic Problems

General Programming on a Parallel Processor

Geocentric Position and/or Orbital Parameters with Star Satellite Photography from a Single Camera Station

Geodetic Control by Means of Astronomic and Torsion Balance Observations and the Gravimetric Reduction of Levelling

Geodetic Control without Triangulation, Trilateration, or Gravity Data and Gravimetric Reduction of Levelling 1st Interim Report 2nd Interim Report 3rd Interim Report

Geodetic SECOR

Geodetic SECOR Ground Equipment

Geodetic SECOR Satellite

Geodetic SECOR Wide-BandRF Subsystem

Geodetic SECOR Wide-Band RF Subsystem for SECOR Ground Equipment Sets

Geodetic SECOR Wide-Band System

Geodetic Spacecraft, Final Report
REPORT NO.

RN-8

1963

ETL-0131

1977

ETL-0199

1979

ETL-0184

ETL-0555

AD 847275

1979

1990

1968

TEC-0049

1994

ETL-CR-70-1

1970

ETL-TR-74-1

1973

ETL-0385

1985

ETL-0008

AD $883289 \mathrm{~L}$

ETL-0287

1975

no date

1982

RN-11

1963

ETL-0062

CR-102-1

1976

1963

AD 672491

1967

AD 447 994L $\quad 1964$

AD $461100 \mathrm{~L} \quad 1965$

AD $477.474 \mathrm{~L} \quad 1965$

AD $721648 \quad 1962$

AD $721649 \quad 1964$

ETL-TR-74-6 1974

AD 721641

AD $824780 \mathrm{~L} \quad 1967$

AD $721640 \quad 1966$

AD $721650 \quad 1961$ 
Geodetic Spacecraft, Addendum

Geodimeter, Models I and II

Geographic Modelling of Insurgency Resources

Geographic Modelling of Insurgency Resources, Appendix

Geoid Representation from Satellite-Determined Coefficients

Geologic Evaluation of Radar Imagery from Darien Province, Panama

Geometric Simultaneous Multistation Determination, with Constraints, Using Data from Geodetic Satellites

Geometrical Quality of Lunar Mapping by Photogrammetric Methods

Geomorphic Evaluation of Radar Imagery of Southeastern Panama and Northwestern Columbia

Geopotential Determination from Satellite to Satellite Tracking and Satellite Altimetry

Geopotential Determination from Satellite to Satellite Tracking and Satellite Altimetry, Supplement I

GEOPS

Geoscience Potentials of Side-Looking Radar, Vol. I

Geoscience Potentials of Side-Looking Radar, Vol. II

Geo-Spin Precision Inertial Survey

Gigas-Zeiss Digital Control Unit

Global Climate Change (GCC) Issues and Their Impacts on the U.S. Army Corps of Engineers

Gradiometer-Aided Rapid Gravity Survey System

Graphic Arts Symbol Generating Hardware for a Gerber Plotting System

Graphic Data Handling Techniques

Gravimetric Geodesy Free of Density Estimates through Analysis of Discrete Gravity Data

Gravity Anomalies as Indicators of Groundwater Reserves in Glacial Deposits

Gravity Correlation Studies for Determination

- of the Gravity Field of the Earth

Gravity Study Program, Final Report

Gravity Study Program, Interim Report
AD $721651 \quad 1961$

1495-TR 1957

AD $848723 \mathrm{~L} \quad 1969$

AD 851 896L 1969

AD $634541 \quad 1966$

AD $853884 \quad 1969$

RN-22

1967

RN-9

1962

ETL-CR-71-2 1971

ETL-CR-74-21 1975

ETL-CR-74-21-S 1975

RN-25

1967

AD $650498 \quad 1965$

AD $650499 \quad 1965$

ETL-0135 1978

ETL-ETR-73-1 1973

TEC-SR-1 1991

ETL-0112 1977

ETL-CR-74-14 1974

AD $659807 \quad 1967$

RN-12 1963

ETL-CR-73-16 1973

AD $866798 \mathrm{~L} \quad 1970$

ETL-0262

1981

ETL-0253 


\section{TITLE}

Ground Target Location Errors Derived From Measurements Collected From a Variety of Hypothetical Satellite Image Understanding Architecture Project, First Annual Report, The Sentinel Systems

Hail and Its Distribution Hexagonal Data Base Study Hexagonal Data Base Study, Phase II High Resolution Optical Power Spectrum Analyzer High Resolution Orthophoto Output Table (HIROOT) High Resolution Orthophoto Output Table

High Speed Disc Memory and a Color Image

Display for a Small Computer

High-Speed, Large-Format Film Writer Methodologies and Design Study

High Speed Parallel Sensing Scheme

History of U.S. Army Engineer Topographic Laboratories (1920 to 1970)

Holographic Compensation of Wavefront Aberrations Holographic Optical Elements With Low Q-Factors Holographic Ray Tracing and Spot Diagrams Holographic Stereogram Display Techniques for the Viewing and Mensuration of Stereo Photogrammetric Imagery

Holographic Terrain Displays

Holography and Stereoscopy

Horizontal Gradients of Gravity in Geodesy Horizontal Gradients of Gravity in S.W. Ohio Hot Weather Testing of 10-Second Direction Theodolite with Universal Tribrach and Universal Tripod, Astronomical Attachment, Universal Sun Compass, Lensatic Compass, and Wrist Compass Air Photo Patterns

Hough Transform on the Butterfly and the NCUBE, The Hourly and Daily Precipitation Frequencies for the United States

Hybrid Methodology for Detecting Cartographically Significant Features Using Landsat TM Imagery

Hyperspectral Gas Analysis System (HyGAS) SBIR Phase I Final Report

Hyperspectral Image Exploitation SBIR Phase I Final Report

Hyperspectral Image Exploitation SBIR Phase II Final Report
REPORT NO. YEAR

ETL-0538

1989

$\begin{array}{ll}\text { ETL-SR-73-3 } & 1973 \\ \text { ETL-0338 } & 1983 \\ \text { ETL-0360 } & 1984 \\ \text { ETL-0127 } & 1978 \\ \text { AD 856 731L } & 1969 \\ \text { ETL-ETR-72-3 } & 1972 \\ \text { AD 878 975L } & 1970 \\ & \\ \text { ETL-0389 } & 1985 \\ & \\ \text { ETL-0119 } & 1977 \\ \text { ETL-SR-74-1 } & 1973 \\ & \\ \text { ETL-RN-74-11 } & 1975 \\ \text { ETL-0123 } & 1977 \\ \text { ETL-0052 } & 1975 \\ \text { ETL-CR-74-2 } & 1973 \\ & \\ & \\ \text { ETL-0083 } & 1976 \\ \text { ETL-CR-72-2 } & 1972 \\ \text { AD 672 492 } & 1964 \\ \text { AD 672 489 } & 1967 \\ \text { 1289-TR } & 1953\end{array}$

ETL-0438

1986

ETL-0498 $\quad 1988$

ETL-0589- $\quad 1991$

TEC-0005 1992

TEC-0004 1992

TEC-0015 1991 


\section{TITLE}

Hyperspectral Signatures (400 to $2500 \mathrm{~nm}$ ) of

Vegetation, Minerals, Soils, Rocks, and

Cultural Features: 1. Laboratory and Field

Measurements

IBIS Query - Software to Support the Image Based

Information System (IBIS) Expansion for Mapping,

Charting, and Geodesy

Image Alignment and Correlation System

Image-Based Approach to Mapping, Charting, and Geodesy

Image Correlation on a Parallel Processor

Image Enhancement by Chemical Intensification

Image Processing for Visual Navigation of Roadways

Image-Processing Precision and Affecting

Relative Orientation

Image Scanner Technology Study

Image Tube Validation Study

Image Understanding Architecture Final Report

Image Understanding Architecture Project,

First Annual Report, The

Image Understanding Architecture Project,

Second Annual Report, The

Image Understanding Architecture Prototype Evaluation and Development

Image Understanding Environment for DARPA Supported

Research and Applications, First Annual Report

Image Understanding Environment for DARPA Supported

Research and Applications, Second Annual Report

Implications of Symbol Usage on U.S. Army

Maps for an Automated Cartographic System

Implications of Symbol Usage on U.S. Army

Maps for an Automated Cartographic System, Appendix

Improvement Program Automatic Map

Compilation System

Improving Classification Accuracy of Radar

Images Using a Mültiple-Stage Classifier

Inertial Platform Subsystem for Army Artillery

Inertial Survey System (GEISHA)

Inertial Positioning System Test Data Summary

Report

Inertial Survey Applications to Civil Works

Inertial Survey Equipment (GEISHA)
REPORT NO.

YEAR

ETL-0573

1990

ETL-0422

1986

ETL-0237

1980

ETL-0366

1982

ETL-0061

1976

ETL-0014

1975

ETL-0406

1985

ETL-RN-71-6

1971

ETL-0137

1978

ETL-CR-70-5

1970

TEC-0029

1991

ETL-0499

1988

ETL-0542

1989

TEC-0044

1993

TEC-0017

1991

TEC-0021

1992

AD 667979

AD 667986

1968

AD 442522

1964

ETL-0502

1988

AD 681931

1962

ETL-0028

1975

ETL-0309

1983

AD 814051 


\section{TITLE}

Inferential Techniques for Soil Depth Determinations, Part I: Coleogyne ramossissima Torr. (Black-Brush)

Inferential Techniques for Soil Depth Determinations, Part II: Artemisia filifolia Torr. (Sand Sagebrush)

Influence of Atmospheric Refraction on Directions Measured to and from a Satellite

Instrument for Measuring Absolute Acceleration of Gravity

Instrument to Measure the Tilt of Large Structures, An

Instrumentation for Color Aerial Photography

Integration of Artificial Intelligence Concepts into the Methods for Extracting Line Objects from Monochromatic Aerial Imagery

Intelligent Advisors for Cross-Country Route Planning

Intelligent TDA Systems Using Neural Networks Phase I Final Report

Interactive Digital Correlation Techniques for Automatic Compilation of Elevation Data

Interactive Digital Image Processing for Terrain Data Extraction

Interactive Digital Image Processing for Terrain Data Extraction, Phase 2

Interactive Digital Image Processing for Terrain Data Extraction, Phase 3

Interactive Digital Image Processing for Terrain Data Extraction, Phase 4

Interactive Digital Image Processing for Terrain Data Extraction, Phase 5

Interactive Digital Image Processing Investigation

Interactive Digital Image Processing Investigation, Phase II

Interactive Image Analysis System Design

Interactive Knowledge-Based Cartographic

Feature Extraction

Interagency Energy and Environmental Survey

Interferometer Data Reduction Study

Interim Solution Rectifier Van

Interim Technical Progress Report, Ninth

SemiAnnual Technical Report, Sep 1971-Mar 1972, Project THEMIS, A Center for Remote Sensing
REPORT NO.

YEAR

ETL-0036

1975

ETL-0176

1979

RN-10

1963

RN-17

1966

ETL-0313

1983

ETL-RN-70-1

1970

ETL-0425

1986

ETL-0365

1984

TEC-0007

1992

ETL-0272

1981

ETL-0241

1980

ETL-0277

1981

ETL-0294

1982

ETL-0348

1983

ETL-0374

1984

ETL-0172

1978

ETL-0221

1980

ETL-0312

1982

ETL-0273

1981

1977

AD $503143 \mathrm{~L} \quad 1969$

1355-TR

1954

ETL-CR-72-4 1972 


\section{TITLE}

Interpolation of Deflections from Horizontal Gravity Gradients

Interpolation of Gravity Anomalies and

Deflection of the Vertical Components from

Rapid Gravity Survey System Data

Interpretation of Radar Imagery for Terrain

Analysis in Tropical Environments

Introduction to the Terrain Effects on the

Intelligence Preparation of the Battlefield (IPB)

Inverse Perspective of a Road from a Single Image

Inverse Scattering Applications in Determining

Terrain Feature Parameters

Investigation and Evaluation of Planigon Lens

Distortion Characteristics

Investigation, Experiments, and Study of Electron

Beam Recorder (EBR) Techniques for Map

Production

Investigation of Bjerhammar's New Gravity

Reduction Method

Investigation of Cartographic Pressplate

Recording from Digital Data

Investigation of Continuous Photoconductive

Layer Arrays

Investigation of Discrete Function Technology for Topographic Sciences

Investigation of Electro-Acoustic Technology for Topographic Application

Investigation of Extrema in Digital Images for Texture Analysis

Investigation of Fusion and Fixation Disparity Limits for Photogrammetry

Investigation of Linear Transformations for Automatic Cartographic Analysis

Investigation of Multiband Photographic Techniques, Vol. I

Investigation of Photographic Mapping Detail and Data Encoding

Investigation of Techniques to Generate Contours from Stereo Pairs

Investigation of the Application of "Array Algebra" to Terrain Modeling

Investigation of the Electronic Distance Measuring Equipment Electrotape
REPORT NO.

YEAR

AD 672490

1967

ETL-0075

1976

1968

ETL-0481

1987

ETL-0429

1986

ETL-0279

1981

1472-TR

1957

ETL-CR-73-15

1973

AD 460404

1964

ETL-0043

1976

ETL-0011

1975

ETL-0162

1978

ETL-0160

1978

ETL-0210

1979

AD 625217

1965

ETL-0181

1979

AD 479 300L

1965

AD 286715

1962

ETL-0029

1975

ETL-0141

1978

AD 460 401L

1964 
Investigation of the Geometrical Quality of the

RN-6

1962

Relative and Absolute Orientation Procedures

and the Final Results of the Photogrammetric

Procedure

Investigation of the Real-Time Accuracy of the DGPS Method

TEC-0024

1992

Investigations into the Problems of Relative

AD $452686 \mathrm{~L}$

1964

Orientation in Stereo Aerial Photogrammetry

Investigations of Basic Geometric Quality of

$\mathrm{RN}-4$

1962

Aerial Photographs and Some Related Problems

Investigations of the Use of Conventional Films

ETL-0177

1979 in the ETL Cartographic EBR

Investigations Related to the Establishment of a

AD 697163

1969

World Geodetic System

IRS: A Simulator for Autonomous Land Vehicle

Navigation

ETL-0455

1987

Joint Analyses in Glen Canyon National

ETL-0073

1976 Recreational Area

Kalman Filtering and Smoothing in Fotonap for

Orbit Determination using GPS Measurements

KANDIDATS

Knowledge-Based Analysis of Scene Dynamics for

Target Motion Detection, Recognition, and Tracking

Knowledge-Based Analysis of Scene Dynamics

for Target Motion Detection, Recognition and

Tracking, Second Annual Report

Knowledge-Based Images Analysis

Knowledge-Based Vision Techniques for the

Autonomous Land Vehicle Program, Final Report

Knowledge-Based Vision Techniques (March 1985

- March 1986)

Knowledge-Based Vision Techniques (March 1986

- March 1987)

Knowledge-Based Vision Techniques: Obstacle

Detection and Avoidance, Fourth Annual Report

Knowledge-Based Vision Techniques, Third

Annual Report

ETL-0161

1978

ETL-CR-71-3

1971

ETL-0486

1987

ETL-0525

1989

Knowledge-Based Vision Techniques for the Autonomous Land Vehicle Program

Knowledge-Based Vision Techniques for the

ETL-0258

1981

TEC-0022

1991

ETL-0431

1986

ETL-0487

1987

ETL-0536

1989

ETL-0521

1988

ETL-0439

1986

Autonomous Land Vehicle (ALV) Program,

ETL-0507

1988 


\section{TITLE}

Knowledge-Based Vision Techniques for the Autonomous Land Vehicle (ALV) Program, Third Annual Report

Knowledge-Based Vision Techniques for the Autonomous Land Vehicle Program Fourth Annual Report

Knowledge-Based Vision Techniques - Task B: Terrain and Object Modeling Recognition Executive Summary

Knowledge-Based Vision Techniques - Task B: Terrain and Object Modeling Recognition (March 13, 1985 March 13, 1986)

Knowledge-Based Vision Techniques - Task B: Terrain and Object Modeling Recognition (March 13, 1986 April 27, 1987)

Knowledge-Based Vision Techniques Task B:

Terrain and Object Modeling Recognition, Third Annual Report

Knowledge-Based Vision Techniques Task B:

Terrain and Object Modeling Recognition -

Volume I: Autonomous Systems for Navigation and Terrain Recognition

Knowledge-Based Vision Techniques Task B:

Terrain and Object Modeling Recognition -

Volume II: Tech Base Vision Research

Knowledge-Based Vision Techniques Task B:

Terrain and Object Modeling Recognition -

Volume III: Image Understanding Software

Environments

KT2 Gyro-Theodolite (Otto Fennel GMBH \& Co)

Land Cover Classification from LANDSAT Data:

Phase III of a Joint OCE/NASA Demonstration

Landforms of Granitic Rocks: An Annotated

Bibliography, The

LANDSAT and DMA Elevation Study

LANDSAT D: Corps of Engineers Interface with

Advanced NASA Ground Systems Study

LASS-II Rapid Geodetic Survey System (RGSS)

Light, Target for Ranging Pole

Lightweight North-Seeking Gyro Azimuth

Surveying Instrument, Model 11NG531A

Lightweight North-Seeking Gyro Azimuth

Surveying Instrument, Model 11NG531B

Linear Feature Extraction from Radar Imagery
REPORT NO.

YEAR

ETL-0512

1988

ETL-0582

1990

ETL-0557

1990

ETL-0428

1986

ETL-0485

1987

ETL-0535

1989

ETL-0558

1990

ETL-0559

1990

ETL-0560

1990

57-TR

1970

ETL-0175

1979

ETL-0566

1990

ETL-0386

1984

ETL-0151

1978

ETL-0518

1986

1402-TR

1955

AD 486317

1965

AD $844011 \mathrm{~L}$

1968

ETL-0405

1985 


\section{TITLE}

Linear Feature Extraction from Radar Imagery, SBIR Phase II Base Contract

Linear Feature Extraction From Radar Imagery:

SBIR Phase II, Option I

Linear Feature Extraction From Radar Imagery:

SBIR Phase II, Option II

L.N.K. Software Systems for Transferring, Merging, and Displaying DFAD/DTED Data on AMS/CAPIR

Local Gravity Field Modeling

Long Range Survey System

Long Range Surveying System

Low Cost Gyrocompass

Low Intensity Conflict Viewer (LIC-VIEW) Phase I

Low Light Level Photography

Manual and Automated Line Generalization and

Feature Displacement

Manual for Maintenance and Operation of the MB-1 Multiband Aerial Camera

Manual of Environmental Effects, Central America

Manual of Environmental Effects, The Countries of Former Yugoslavia and Albania

Manual of Environmental Effects, The Horn of Africa

Map Coating Concept Studies

Map Illuminator Test, Phase I

MAPCON Design Study

Mapping Camera Image Errors Due to Star

Camera Identification and Measuring Errors

Mapping from Airborne Radar Scope Presentations

Mapping from Radar Presentations, Second Interim Report

Mapping from Side-Looking Radar

Mapping with Minimum Ground Control

MAT Transponder Model No. 10002

Materials Research for Holographic Recording

(Report No. 1, Multiple Image Storage of

Continuous Tone Data in Volume Holograms)

Materials Research for Holographic Recording

(Report No. 2, Bleaching Methods for

Photographically Recorded Holograms)

Materials Research for Holographic Recording

(Report No. 3, Hardened Gelatin Holographic

Recording Materials)

Mathematical Analysis of a Technique for the

Calibration of a Synthetic Aperture Radar
REPORT NO.

ETL-0469

1987

ETL-0497

1988

ETL-0530

1988

ETL-0318

1983

ETL-0448

1986

AD $356441 \mathrm{~L}$

1964

AD 328203

1960

ETL-0355

TEC-0043

1984

32-TR

1992

1966

ETL-0359

1984

ETL-0040

1976

TEC-SR-2

1992

TEC-SR-5

1993

TEC-SR-4

1992

AD 679215

1968

ETL-0034

1975

AD 854 619L

1967

ETL-RN-73-1

1973

1958

1397-TR

1955

AD $392041 \mathrm{~L}$

1968

1483-TR

1957

AD 721638

1967

ETL-0088

1976

ETL-0156

1978

ETL-0197

1979

43-TR

1968 


\section{TITLE}

Mathematical Method for Inversion in Atmospheric Remote Sensing, A

Mathematical Techniques for Automated Cartography

Mathematics of Geodetic SECOR Data Processing

Matrix Evaluation of Remote Sensor Capabilities for Military Geographic Information (MGI)

MATS Performance with the SECOR System

MATS Transponder

Measurement of the Change in the Deflection of of the Vertical with a Schuler-Tuned NorthSlaved Inertial System

Measurement Techniques of Electrical Parameters of Surface Materials in the X-Band Region

Mechanization Design, Performance Simulations, and Cost Trade-Offs Hybrid INS/GPS/PLRS Positioning and Orientation Systems

Mensuration and Reduction Accuracy and Precision Standard Applicable to an Integrated WorldWide Topographic System

Methodological Preliminaries to the Development of an Expert System for Aerial Photo Interpretation

Methodology for Military Geographic Analysis

Methods and Results of Remote Barometric Altimetry and Views on the Estimation of Meteorological Field Variables

Methods for Calculating Atmospheric Refraction and Its Perturbation

Methods of Monitoring the Persian Gulf Oil Spill Using Digital and Hardcopy Multiband Data

Micromap Camera for Display Systems

Microreduction and Enlargement of Graphic Information Study (MEGIS)

Microwave Pointing Variations and Angle Measurements

Military Applications of Multiband Aerial Photography (Report No. 5 in the ETL Series on Remote Sensing)

Military Geographic Intelligence Products Associated with the SLAR Topo Map Test in Panama

Military Potential Test of Selected Items of Hydrologic Survey Equipment
REPORT NO.

YEAR

ETL-0346

1983

ETL-CR-73-4

1973

AD 721837

1964

ETL-TR-72-6

1972

AD 721635

AD 721634

no date

ETL-0138

1966

1977

ETL-0304

1982

ETL-0409

1985

58-TR

1970

ETL-0342

1984

36-TR

1967

ETL-RN-73-3

1973

ETL-0299

1982

TEC-0014

1992

ETL-ETR-71-5

1971

ETL-0063

1977

26-TR

1966

ETL-0030

1975

ETL-ETR-70-10

1970

AD 890746

1971 
TITLE

Military Significance of the USAETL Research

Note "A New Solution for the Anomalous Gravity

Potential Resulting from a Modification of

Molodensky's Linear Approximation, Its Practical

Significance, and Numerous Ramifications"

Miniaturized Gyrocompass

Miniaturized Gyrocompass (Small North-Orienting Device)

Minipim-MK II Precision Indicator of the Meridian (British Aircraft Corp.)

Mini Raster-to-Vector Conversion

Mod II Power Supply for Army Artillery Inertial Survey System (GEISHA)

Modeling and Contouring Irregular Surfaces

Subject to Constraints

Modes of Satellite Triangulation Adjustment, Vol. I

Modes of Satellite Triangulation Adjustment, Vol. II

Modification of a Cartographic Mapping Camera

from Type T-11 to Type KC-4B (with Automatic Exposure Control)

Modification of the MUSAT Aerotriangulation

Programs to Accommodate Bathymetric Image

Points

Modifications to FOTONAP

Mono Versus Stereo Analytical Photogrammetry, Part 1

Mono Versus Stereo Analytical Photogrammetry, Part 2

Morphometry of Landforms: Quantification of Slope Gradients in Glaciated Terrain

Motion Analysis and Object Recognition for Autonomous Navigation

Multi-Altitude Transponder - Volume I, Schematic Diagrams

Multi-Altitude Transponder - Volume II, Part 1, Test

Procedures and Results of Test MATS Transponder

Multi-Altitude Transponder - Volume II, Part 2

Multi-Altitude Transponder - Volume II, Part 3

Multi-Altitude Transponder - Volume II, Part 4

Multi-Altitude Transponder - Volume II, Part 5

Multi-Altitude Transponder - Volume III, Final Reliability Report

Multi-Altitude Transponder - Volume IV, Design

Considerations and Component Selection Criteria
REPORT NO.

YEAR

RN-34

1970

ETL-0289

1982

ETL-ETR-70-11 1970

45-TR

1969

ETL-0269

1981

AD 814067

1963

ETL-CR-74-19

1975

AD 633863

1966

AD 633864

1966

ETL-TR-71-1

1971

ETL-0306

1983

ETL-0116

1977

AD 664184

1967

AD 828750

1968

ETL-RN-72-3

1972

TEC-0020

1991

AD 721636 no date

AD 721628 no date

AD 721629

AD 721630

1967

AD 721631

AD 721632

AD 721637

no date

no date

1967

AD 721633

no date 
Multi-Image Correlation Systems Study for MGI

AD 841079

1968

Multi-Image Correlation Systems Study,

AD 870453

1969

Quantitative Evaluation of Electronic

Multi-Image Processor

Multi-Image Pattern Recognition: Ideas and

AD 863596

no date

Results

Multi-Parametric Figures of Equilibrium:

AD 603073

1964

Curvature of the Plumb Line

Multi-Parametric Theory of Spheroidal

Equilibrium Figures and the Normal-

Spheroids of Earth and Moon

Multispectral Image Maps from Landsat Thematic Mapper Data

Multiple Camera Analytical Triangulation Program

ETL-0590

1991

Multiple Station Analytical Triangulation Program

Multipower Army Stereoscope

Multisensor Approaches for Determining

Deflections of the Vertical

Multisensor Study of Plant Communities at

Horsefly Mountain, Oregon

Multisource Image Analysis

Multispectral Capability of H\&W Film

(Photographic Technology Series)

Multispectral Target Signatures

Multivariate Spectral Analysis to Extract Materials from Multispectral Data

MUSAT IV

AD 638750

1965

12-TR

ETL-0314

1983

AD $698098 \quad 1969$

ETL-0208

1979

ETL-0101

1977

ETL-0165

1978

TEC-0039

1993

ETL-CR-70-6

1970

Natural Image Computers, Vol. I

AD 856 137L

Natural Image Computers, Vol. II

AD 856 138L

1967

Near-Real-Time Application of Digital Terrain

ETL-0142

1978

Data in a Minicomputer Environment

Near-Surface Bathymetry System (Report No. 11

in the ETL Series on Remote Sensing)

Neural Networks for Object Detection Using

ETL-0163

1978

All-Source Imagery

New Analyses and Methods Leading to Improved Acquisition Requirements Involving Systems, Geodetic and Reentry Errors, and Increased Weapons

Effectiveness for Conventional Weapons (Part I)

New Analyses and Methods Leading to Improved

Acquisition Requirements Involving Systems,

ETL-RN-70-3

1970

Geodetic and Reentry Errors, and Increased

Weapons Effectiveness for Conventional

Weapons (Part II) 
Parameters or Orientation

New Insights and Results Regarding L.F.

ETL-RN-72-2 1972

Richardson's Turbulence Criterion

New Large-Scale, High-Resolution, Multicolor Software Display Concept, A

New Method for Determining Azimuth and Latitude Independent of Time and Zenith Distance

New Methods of Change Detection Using Multispectral Data

New Solution for the Anomalous Gravity Potential Resulting from a Modification of Molodensky's Linear Approximation, Its Practical Significance and Numerous Ramifications, A

1986 Year End Report for Road Following at Carnegie

ETL-0464

1987 -Mellon

1987 Year End Report for Road Following at Carnegie-Mellon

ETL-0514

1988

1988 Year End Report for Road Following at

ETL-0537

1989 Carnegie-Mellon

Noise Removal on Radar Imagery Using Local

ETL-0402

1985 Gradient and Statistics

Noncontact Array Velocimeter

Non-COTS Displays: The Display Technology of the Future

ETL-0077

1976

North-Seeking Gyrocompass, Final Technical Report

Observations on Multi-Peg Towers of Hanoi

Occurrence of Ice in the Form of Glaze, Rime, and Hoar-Frost with Respect to the Operation and Storage of V/STOL Aircraft

On Computing Histograms of Images in Log $\eta$ Time

TEC-0054 Using Fat Pyramids

On the Energy Integral for Satellites

On the Thermal Nature and Sensing of Snow-Covered Arctic Terrain

Optical-Electronic Precision Pointing System

Optical Power Spectral Analysis for Machine-Readable Factor Maps

ETL-0476

1986

ETL-SR-73-1 1973

Optical Power Spectrum Analysis (OPSA)

(Report No. 1 Recording Optical Spectrum

ETL-0454

1987

RN-29

1968

ETL-RN-73-4 1973

Analyzer System Hardware) 
TITLE

Optical Theodolite Readout

Optimized Digital Automatic Map Compilation System 1st Interim Report

2nd Interim Report

3rd Interim Report

4th Interim Report

Optimized Method for the Derivation of the

Deflection of the Vertical from RGSS Data

Optimized Post-Mission Determination of the

Deflection of the Vertical Using RGSS Data

Orthographic Radar Restitutor Engineer Design

Test

Orthophoto Viewer and Transfer Device

Overview of Vision-Based Navigation for Autonomous

Land Vehicles 1986, An

Parallel Algorithms for Computer Vision

Parallel Algorithms for Computer Vision, Second Year Report

Parallel Algorithms for Computer Vision, Third Year Report

Parallel Algorithms for Computer Vision, Final Report

Parallel Optical Processing to Convert Elevation Data to Slope Maps. Phase I: Theoretical Analysis

Parallel Optical Processing to Convert Elevation Data to Slope Maps. Phase II: Practical Considerations

Parallel Profile Plots for Visual Terrain Display

Parallel Vision Algorithm Design and Implementation, 1987 End of Year Report

Parallel Vision Algorithm Design and Implementation, 1988 End of Year Report

Parallel Vision Algorithms, First Annual Technical Report

Parallel Vision Algorithms, Second Annual Technical Report

Parser for the ISO 8211 Data Format, A

Particulate Matter Considerations in the Design of V/STOL Aircraft

Passive Recovery of Scene Geometry for an Unmanned Ground Vehicle

Passive Recovery of Scene Geometry for an Unmanned Ground Vehicle, Second Annual Report
REPORT NO. YEAR

AD $821660 \mathrm{~L} \quad 1967$

AD $412798 \quad 1963$

AD $422227 \quad 1963$

AD $432243 \quad 1963$

AD $600117 \quad 1964$

ETL-0122 1977

ETL-0164 1978

ETL-ETR-74-6 1974

AD $722788 \quad 1965$

ETL-0479 $\quad 1987$

ETL-0456 1987

ETL-0495 $\quad 1988$

ETL-0528 $\quad 1989$

ETL-0564 1990

ETL-RN-74-9 1974

ETL-RN-74-12 1975

ETL-0115 1977

ETL-0513 1988

$\begin{array}{ll}\text { ETL-0541 } & 1989\end{array}$

$\begin{array}{ll}\text { ETL-0488 } & 1987\end{array}$

$\begin{array}{ll}\text { ETL-0529 } & 1989\end{array}$

TEC-0045 1994

ETL-SR-72-2 1972

TEC-0033 1993

TEC-0053 1994 
TITLE

Pattern Classification Techniques Applied to High

Resolution, Synthetic Aperture Radar Imagery

PDEF: A Standard File Format for Data Interchange

Perception for Outdoor Navigation - First Year

Report

Performance Evaluation of the Position and

Azimuth Determining System (PADS) with an

Improved Vertical Accelerometer

Personal Navigation and Reporting - Phase I (Cybernet)

Personal Navigation and Reporting - Phase I (Levi)

Phoenix Laser and Terrain Profile Test

Photo Analysis of a Desert Area

Photo-Geomorphology of Coastal Landforms, Cat Island, Bahamas (Vol. II)

Photogrammetric and Tracking Network Analysis Program

Photogrammetric and Tracking Network Analysis Program for the UNIVAC 1108 Computer

Photogrammetric Applications to Field Artillery

Photogrammetric Aspects of the Heterodyne Optical Correlator

Photogrammetric Flash Triangulation for Corps

of Engineers Field Use

1st Interim Report

2nd Interim Report

3rd Interim Report

Final Report

Photogrammetric Reduction for ATL

Photographic Visibility of Light Images on

Aerial Film

Photomap Reproduction System

Physical Characteristics of Some Soils from the Middle East

Pilot Program of Lunar Photography for Precise Selenodesy

Plastic-Scribing Color Separation for Military Cartography

Platform Orientation System Test Program

Point Light Source Contact Printer Photographic Technology Series

Position and Azimuth Determining System (PADS)

Position and Azimuth Determining System (PADS) Helicopter Study

Position and Surveying System (PASS)

Possibility of Adapting a Land Navigation

System to Perform Artillery Survey
REPORT NO.

YEAR

ETL-0443

1986

ETL-SR-7

1991

ETL-0581

1990

ETL-0166

1978

TEC-0036

1993

TEC-0037

1993

1966

ETL-0068

1976

ETL-SR-74-5

1974

ETL-CR-73-17

1973

ETL-0018

1975

56-TR

1970

ETL-0095

1976

AD 265036

AD 271438

AD 271439

AD 223674

1960

1961

1961

1961

1961

1966

AD $882566 \mathrm{~L}$

1965

TEC-0032

1993

AD 452237

1964

1485-TR

1957

ETL-0100

1976

ETL-0084

1976

ETL-ETR-74-1 1974

ETL-0009

1975

ETL-CR-73-11

1973

ETL-0078 


\section{TITLE}

Post-Mission Smoothing and Analysis of the

Measurements of the Change in the Deflection

of the Vertical Obtained by the Rapid

Geodetic Survey System (RGSS) at the

White Sands Test Range

Potential of Thermal IR Imagery for Supplemental Map Information in Snow-Covered Areas

Potential Sand and Dust Source Areas

Practical Field Accuracy Limits for a Wild T-2 Theodolite

Practical Second-Order Theory for the Disturbance Potential and Deflections of the Vertical, Including an Analysis of the Limitations of the Molodensky/Brovar Series and Downward Continuation of Gravity

Practical Tests of the Theoretical Accuracy of Aerial Triangulation

Precise Photogrammetric Orientation and Data Determination of HIRAN Mapping System AN/APQ 73

Precision Enlarging Printer (4X)

Precision 2.0X Enlarging Printer

Precision 3.3X Enlarging Printer

Precision STARAN Correlator

Predesign Data for the Radar Stereo Equipment Program

Preliminary Image Data Extraction Experiments with the Phase I, Automated Image Data Extraction System-I

Preliminary Radar Feature Extraction and Recognition Using Texture Measurement

Preliminary Reliability Prediction - MATS

Preliminary Study into the Principles of Continuous Tone Electrophotography

Preproduction Model Cartographic EBR System

Proceedings of the International Symposium

Figure of the Earth and Refraction

Product Improvement Test Report of Astronomic

Surveying Equipment

Production of Dense Range Images with the

CVL Light-Stripe Range Scanner

Program and Test Procedures to Determine the

Geocentric Coordinates and Orbital

Parameters of an Unidentified Satellite

Program Maintenance Manual for the Reference

Scene Software (RSS)
REPORT NO.

YEAR

ETL-0065

1976

ETL-0059

1976

ETL-SR-72-1

1972

30-TR

1966

ETL-RN-71-1

1971

RN-1

1962

AD 238857

1960

27-TR

1966

55-TR

1970

ETL-ETR-71-3 1971

ETL-0133

1977

AD 701169

1969

ETL-RN-74-7

1974

ETL-0315

1983

AD 721639

1965

AD 401863

1962

ETL-0246

1980

AD 825792

1967

28-TR

1966

ETL-0491

1988

AD 617698

1968

ETL-0067

1976 


\section{TITLE}

Programmer for Army Artillery Inertial Survey System (GEISHA)

Programming Environment for Parallel Vision

Algorithms, A (February 1985 - February 1986)

Programming Environment for Parallel Vision

Algorithms, A (February 1986 - February 1987)

Programming Environment for Parallel Vision

Algorithms, A - Final Technical Report

Programming Environment for Parallel Vision Algorithms, Third Annual Report, A

Project Ostrich A Feasibility Study: Detecting Buried Mines in Dry Soils Using Synthetic Aperture Radar

Project SAND - Availability of Construction Materials in the Mekong Delta

Project SAND (Phase III) - Analysis of Remote Sensor Imagery of Selected Areas in the Mississippi Delta

Project THEMIS: A Center for Remote Sensing

Study Plan

Progress Report

Interim Report

Progress Report

Progress Report

5th Semi-annual Report

6th Semi-annual Report

7th Semi-annual Report (ETL-CR-71-7)

8th Semi-annual Report (ETL-CR-71-21)

Final Report (ETL-CR-74-10)

Propagation of Very Short Radio Waves Through

the Ionosphere and the Investigation of

Ionospheric Models

Proposed Stereophotogrammetric System for

Topographic Mapping from Photography

Taken at Altitudes up to 100,000 Feet

Prototype Automatic Mosaicking System

Prototype Electrostatic Image Reproducer

Prototype Image Spectrum Ánalyzer (PISA)

for Cartographic Feature Extraction

Prototype Lithographic Enlarging Projection

Platemaker

Prototype Stereomat System

Quantitative Geography: Achievements and Prospects
REPORT NO.

YEAR

AD 814065

1963

ETL-0433

1986

ETL-0457

1987

ETL-0563

1990

ETL-0510

1988

TEC-0040

1993

Tech Memo 156-1 1968

ETL-TR-71-3

1971

AD 690361

1968

AD 847276

1968

AD 683584

1968

AD 853884

1969

AD 864859

1969

AD 869511

1970

AD $879981 \mathrm{~L}$

1970

AD 726966

1971

AD 735752

1971

AD A003 266

1974

ETL-RN-74-1

1973

1518-TR

1958

17-TR

1963

ETL-0035

1973

ETL-0204

1979

ETL-ETR-72-4 1972

4-TR

1962

ETL-CR-71-12

1971 
TITLE

RACOMS Cartographic Module

RACOMS Compilation Module I

RACOMS Data Processing Module

RACOMS Image Processing Module I

RACOMS Image Processing Module II

RACOMS Map Revision Module

RACOMS Operations Module

RACOMS Pass Point Marking and Measuring

Instrument

RACOMS Reproduction Module

Radar Backscatter from a Vegetated Terrain: A

Discrete Scattering Approach

Radar Bridge Patterns Extraction and Recognition

Radar Image Simulation of Seasonally Dependent Reference Scenes

Radar Image Simulation Project

Radar Image Simulation Project: Development of a General Simulation Model and an Interactive Simulation Model, and Sample Results

Radar Image Simulation: Validation of the Point Scattering Model, Volume I

Radar Image Simulation: Validation of the Point Scattering Model, Volume II

Radar Image Simulation: Validation of the Point Scattering Method Addendum

Radar Mapping Beacon Analysis

Radar Mapping Test Ranges

Radar Network Adjustment

Radar Presentation Restitutor

Radar Sketching Device

Radar Stereo Equipment Program

Radar, Thermal Infrared, and Panchromatic Image Collection and Analysis

Radiative Transfer in One-Dimensional Discretely Stratified Media

RADOT Code for the Tracking of Radar Incident on Trees

RADOT Code System to Calculate the Radar Return from a Forested Area

Rainfall Intensities in the Conterminous United

States and Hawaii (Supplement 1 to ETL-SR-72-5:

Distribution of Mean Monthly Precipitation and Rainfall Intensities)

Range Imagery Algorithms for the Detection of Obstacles by Autonomous Vehicles

Rapid Cartographic Processing System Study
REPORT NO.

YEAR

ETL-ETR-70-3 1970

ETL-ETR-70-1 1970

ETL-ETR-70-4 1970

47-TR

1969

ETL-ETR-70-2 1970

ETL-ETR-70-5 1970

44-TR

1969

53-TR

1970

ETL-ETR-71-1 1971

ETL-0159

1979

ETL-0323

1983

ETL-0188

1979

ETL-0098

1976

ETL-0047

1976

ETL-0117

1977

ETL-0118

1977

ETL-0155

1978

ETL-CR-73-22

1973

AD 231433

1959

1962

1956

20-TR

1965

AD $732875 \quad 1971$

ETL-0249

1980

ETL-0236

1980

ETL-0147

1978

ETL-0206

1979

ETL-SR-74-3

1973

ETL-0461

1987

AD 454 086L

1964 


\section{TITLE}

Rapid Combat Mapping System Evaluation

Rapid Geodetic Survey System

Rapid Geodetic Survey System (RGSS) Deflection of the Vertical and Gravity Anomaly Tests at White Sands Missile Range, 1980

Rapid Gravity Survey System Aided with Supplemental Gravimetric Data

RC-135A/USQ-28 Category II Test (The Photographic Resolution Capabilities of the KS-78A Camera Subsystem)

R\&D Plan for Army Applications of AI/ROBOTICS

Recognition of Handprinted Symbols for ComputerAided Mapping

Recording and Scanning Advances in Cartographic EBR Systems

Reduction and Classification of the Data Base List

Reduction Procedures for Absolute Direction and Geodetic Azimuths from Optical Observations of Satellites

Reflection and Identification Studies Applied to Terrain Imaging Radar

Refraction in Selected Model Atmospheres

Registration of a LANDSAT Image to a DTM An Error Analysis

Relation Between the Spectrum of Surface Slopes and the Spectrum of Surface Elevations and its Usefulness in the Theory of Electromagnetic Wave Scattering from Rough Surfaces

Relational Data Base Management Study

Relative Mapping Triangulation Program, Vol. I

Relative Mapping Triangulation Program, Vol. II

Relative Mapping Triangulation Program, Vol. III

Relative Mapping Triangulation Program, Vol. IV

Remote Sensing Field Guide - Desert

Remote Sensor Image Capabilities for Acquisition of Terrain Information

Remote Sensor Imagery Analysis for Location of Construction Materials in the Mekong DeltaProject SAND (Phase II)

Replacement of Photographic Imagery Equipment (RPIE)

Report on Atmospheric Obstructions to Visibility: Volume I - Study Results

Report on Atmospheric Obstructions to Visibility: Volume II - Results of Literature Search
REPORT NO. YEAR

ETL-ETR-70-8 1970

ETL-0074 1976

ETL-0308 $\quad 1982$

ETL-0113 1977

TM-69-1 1969

ETL-0296 1982

ETL-CR-71-27 1971

ETL-0265 1981

AD $817518 \quad 1967$

RN-14 1965

ETL-0331 1983

AD 404465

ETL-0350 1984

ETL-RN-70-2 1970

ETL-0136 1978

AD $721601 \quad 1969$

AD $721602 \quad 1969$

AD $721603 \quad 1969$

AD $721604 \quad 1969$

ETL-0588 1991

ETL-0054 1976

52-TR

1970

ETL-0038

1976

ETL-0169

1979

ETL-0170

1979 


\section{TITLE}

Representation, Modeling and Recognition of Outdoor Scenes

Representation, Modeling and Recognition of Outdoor Scenes Second Annual Report

Research and Design of a PROM Coherent Optical Processor

Research and Development Acceptance Test Report Surveying Instrument: Azimuth, Gyro, Lightweight (Lear Siegler, Inc. Models)

Research and Development of a Prototype Laser Point Marking Instrument

Research in Expert Interactive Cartographic Systems

Research in Knowledge-Based Vision Techniques for the Autonomous Land Vehicle Program (June 1, 1985 - May 31, 1986)

Research in Knowledge-Based Vision Techniques for the Autonomous Land Vehicle Program (June 1, 1986 - May 31, 1987)

Research in Knowledge-Based Vision Techniques for the Autonomous Land Vehicle Program Third Annual Report

Research in Knowledge-Based Vision Techniques for the Autonomous Land Vehicle Program

Final Annual Report

Research in Space Photogrammetry

Research in Surveying, Mapping and Geodesy

Research Institute Lectures on Geography

Research on Refinement and Interpretation of

Gravity Anomaly Computations

Research Studies Related to Mapping, Geodesy, and

Position Determination - Summary Report

Research Studies Related to Mapping, Geodesy, and Position Determination

Research Studies Related to Mapping, Geodesy, and Position Determination

Interim Report No. 10

Interim Report No. 11

Interim Report No. 13

Interim Report No. 14

Interim Report No. 15

Research Studies Related to Mapping, Geodesy, and

Position Determination - Final Report

Results of Earth Observation Study on STS-31 for Terra Geode

Results of Space Triangulation Adjustments from Satellite Data
REPORT NO.

YEAR

TEC-0046

1993

TEC-0057

1994

ETL-0219

1980

23-TR

1965

AD 673291

1967

ETL-0417

1986

ETL-0444

1986

ETL-0482

1987

ETL-0522

1988

ETL-0545

1989

AD 722789

1961

AD 230066

1959

ETL-SR-71-1

1971

AD 831840

1968

1960

AD 286300

1961

AD 286297

1961

AD 286298

1961

AD 286299

1962

AD 284969

1962

AD 298584

1962

AD 402602

1963

TEC-0009

1992

$\mathrm{RN}-13$

1965 
Review and Analysis of U.S. Army Geodetic SECOR

AD 818483

1962

System and Development

Review of New Geographic Methods and Techniques,

AD 700151

1969

Vol. I

Review of New Geographic Methods and Techniques, Vol. II

Review of Photosensitive Materials for

AD $700176 \quad 1969$

Holographic Recordings

Road Boundary Detection for Autonomous Vehicle Navigation

Road Detection on Radar Imagery

ETL-0128

1978

ETL-0407

1985

ETL-0403

1985

Robotic Vehicle Terrain-Navigation Subsystem: Conceptual Design Phase

Robust Image Understanding - Techniques and Applications - First Annual Report

Robust Image Understanding - Techniques and Applications - Second Annual Report

RPIE Symbol Placement Accuracy

Ruggedized Geodetic SECOR

Ruggedized Geodetic SECOR System

RWPF Spatial Data Study

ETL-0332 $\quad 1983$

ETL-0580 $\quad 1990$

Sand and Dust Considerations in the Design of Military Equipment

Satellite Angulateration

Satellite Geodesy Based on Stellar Orientation of Lines Between Unknown Stations

Satellite Observations of Widespread Fog

Satellite-to-Satellite Tracking for Orbit Improvement and Determination of a $1^{\circ} \times 1^{\circ}$ Gravity Field

Satellite-to-Satellite Tracking Study for the Global Positioning System (Rotating-Y Configuration)

Satellite, U.S. Army Type II, Geodetic, Final Report Volume 1

Volume 2, Appendix, Antenna Patterns

Volume 3, Appendix, Environmental Test Results

Scale Problems in Geographic Research

Scattering from a Vegetation Layer with an Irregular Vegetation Soil Boundary

Scattering of a Code-Modulated Radio Signal

TEC-0050

1993

ETL-0076

1976

AD 722642

1964

ETL-0367

1967

1984

ETL-TR-72-7 1972

$\mathrm{RN}-16$

1965

RN-32

1969

ETL-0361

1984

ETL-0064

1976

ETL-SR-74-6

1974 and Associated Multipath Range Errors

Scene Classification Results Using the

AD $871283 \quad 1963$

AD $871284 \quad 1964$

AD $871285 \quad 1964$

ETL-CR-71-16 1971

ETL-0270 1981

ETL-0125 $\quad 1977$

ETL-0300 1982 Max-Min Texture Measure 
Selected Bibliography of Corps of Engineers

ETL-0126

Remote Sensing Reports

Selection of Climate Station Data Using Clustering

and Triangulated Irregular Network Techniques

TEC-0041

1993

Semiautomatic Coordinate Reader

ETL-ETR-71-4 1971

Semi-Automatic Pass Point Determination

ETL-0051

1975

Using Digital Techniques

Sensing Array System with Image Statistics

ETL-0297

1983

Processing, A

Sentinel Satellite Positional Precision Derived

from the NAVSTAR Global Positioning System

ETL-0544

1989

Sequential Independent Model Block Analytical

AD $805606 \mathrm{~L}$

1966

Triangulation (SIMBAT)

Service Tests and Subsequent Modifications and

Test of Compass Sun, Universal, 0 to 90

Degrees North and South Latitudes, with Case

Shaded Relief Images for Cartographic

Applications

Shape from Projecting a Stripe Pattern

Side-Looking Radar Data Requirements for

Automated Mapping on the UNAMACE

Side-Looking Radar Presentation Viewing and

Measuring Instrument

Signal Signatures of Topographic Features

Using Analog Technology

Simple Analytical Methods for Estimating Short-

Term Rainfall

Simple Computer Database System for UNIX, A

1422-TR

1955

ETL-0259

1981

ETL-0453

1987

ETL-CR-72-18

1972

22-TR

1965

ETL-0185

1979

ETL-0441

1986

Simplified Electrostatic Color Printing

ETL-0494

1988

ETL-0421

1986

Simulation of a Radar Image for Garden City

ETL-0007

1975

Test Site

Single-Lens, Four-Channel Multiband Camera

ETL-ETR-74-4

1974

(Report No. 3 in the ETL Series on Remote

Sensing)

Single Photo Analysis of Sampled Aerial Imagery

Site Model Based Image Registration and Change

Detection - First Annual Report on RADIUS

Project

Smart Environmental Monitor Based on Neural Networks

and Multi-Spectral Pattern Recognition

ETL-RN-74-10

1974

Smart Mapping, Charting and Geodesy Control

Generator, Phase I, A

Smart Mapping, Charting and Geodesy Control

Generator, Phase II, A

TEC-0055

1994

TEC-0048

1993

ETL-0458

1987

ETL-0523

1988 
Software Conversion of Standard Linear Format ETL-0394

Prediction Expert System

Solution of the General Analytical

AD $202318 \quad 1958$

Aerotriangulation Problem

Some Relations Between the Geometrical Quality

RN-7

1962

of Topographic Mapping and Aerial

Photogrammetry

Sparse Area Stereo Matching Experiment

Spatial Data Structures for Robotic Vehicle

Route Planning

Spatial Light Modulators: Test and Evaluation

Spatial Sampling: A Technique for Acquisition of Geographic Data from Aerial Photographs and Maps

Spatial Target Location Errors Derived From

ETL-0532

1989

Measurements Collected From Sixteen Satellite

ETL-0424

1986

ETL-0520

1988

ETL-0192

1979

ETL-CR-71-11

1971

Constellations

Spectral Reflectivity Data: A Practical Acquisition Procedure

AD 880 049L $\quad 1970$

Spectral/Spatial Resolution Targets for Aerial Imagery (Report No. 1 in the ETL Series on Remote Sensing)

Stable Platform Assembly for Army Artillery Inertial Survey System

Stable Platform Electronics for Army Artillery Inertial Survey System (GEISHA)

Star Pattern Recognition and Spacecraft Attitude Determination

Star Pattern Recognition and Spacecraft Attitude Determination, Phase II

Star Pattern Recognition and Spacecraft Attitude Determination, Final Report

STARAN Image Processing

Stars' Position Determined by Combining Micrometric Observations with an Observed Known Star in a Vertical Plane Close to the Meridian

State-of-the-Art Assessment of Automatic Name Placement, A

State-of-the-Art of Slope Mapping

Statistical Analysis of Geomorphic, Petrographic and Structural Characteristics of the Dartmoor Tors, Southwest England

$\begin{array}{ll}\text { AD 681 932 } & 1962 \\ \text { AD 681 933 } & 1962 \\ \text { ETL-0173 } & 1978 \\ \text { ETL-0211 } & 1979 \\ \text { ETL-0260 } & 1981 \\ \text { ETL-0243 } & 1980 \\ \text { RN-20 } & 1967 \\ & \\ \text { ETL-0427 } & 1986 \\ \text { ETL-0060 } & 1976 \\ \text { TEC-0027 } & 1993\end{array}$


Status of Aerial Color Photography in

TB-1

1968

Government Agencies

Stereo Analysis of a Specific Digital Model

ETL-0072

1976

Sampled from Aerial Imagery

Stereo Radar Analysis

Stereo Radar Techniques Study, Phase I,

AD 903 321L

1970

Vol. 1 - Analysis

AD 800 171L

1966

Stereoplotter, Topographic, Projection-Type

High Precision

1627-TR

1960

Stereoscopic Terrain Display for Measurement

ETL-0002

1974 Applications

Stress Analysis, Study of the M4 Van Expansible

AD 636445

1966 and Adapter, Detachable Running Gear

Structural Analysis from Radar Imagery, Eastern

AD 715322

1970

Panamanian Isthmus

Studies in Zinc Oxide Photoconductivity

Studies of Gravity in Space According to

AD 673836

1968

AD $485687 \mathrm{~L}$

1966

Bjerhammer

Study and Analysis of the Position and Azimuth

ETL-CR-74-22

1974

Determining System (PADS) Field Maintenance Concept

Study and Analysis of the Position and Azimuth

ETL-CR-73-12

1973

Determining System (PADS) for Mapping,

Charting, and Geodesy Applications

Study and Prototype Model Design of a Miniaturized Gyrocompass, Interim

Study and Prototype Model Design of a Miniaturized Gyrocompass, Final

Study of a Digital Interface Design for the Quick Response Multicolor Printer (QRMP)

Study of Classification and Nomenclature of Vegetation

Study of Digital Matching of Dissimilar Images

Study of Environmental Monitoring and Information Systems

Study of Knowledge-Based Systems for Photo Interpretation

AD 462322

1964

AD 465330

1965

ETL-0327

1983

ETL-0058

1976

ETL-0248

1980

ETL-CR-72-1

1972

ETL-0235

1980

Study of Lithographic Fountain Solutions

Study of Panoramic-Metric Image Matching for

AD 830 674L

Photogrammetric Instrumentation

AD $474839 \mathrm{~L}$

1965

Study of Potential Application of Holographic

ETL-CR-70-8

1970

Techniques to Mapping (Interim Report)

Study of Potential Application of Holographic

Techniques to Mapping (Final Report)

Study of Raster Metafile Formats

ETL-CR-71-17

1971

ETL-0363

1984 


\section{TITLE}

Study of Solution of a Large System of

Linearized Normal Equations and the Inversion

of the Associated Coefficient Matrix

Study of Stereophotogrammetric Systems for

Topographic Mapping with Very High Altitude

Aerial Photography

Study of Visual Stereoscopic Acuity

Study of the Accuracy of Visual Planimetric

Pointings to Photographic Edges with

Different Characteristics

Study of the Application of Piezoelectric

Techniques to a Small North-Orienting Device

Study of the Characteristics of the Holographic

Stereomodel for Application in Mensuration and

Mapping (Part I of Final Report)

Study of the Characteristics of the Holographic

Stereomodel for Application in Mensuration and

Mapping (Part II of Final Report)

Study of the Effect of Corona Conditions on

Electrostatic Processes

Study of the Effects of Nonhomogeneous Target

Backgrounds on Photogrammetric Coordinate

Measurement

Study of the Human Visual System in Support of

Automated Feature Extraction

Study of the Impact of the Global Positioning

System on Army Survey

Study of the Interaction of a Positive Corona

with Selenium Coatings Relevant to the IFAX

Printing Process

Study of the Long Range Position Determination

System

Study to Establish a Method of Selecting Input

Photographic Material for Automated

Compilation Equipment

Study to Optimize Performance of the Rapid

Geodetic Survey System - Interim Technical

Report

Study to Optimize Performance of the Rapid

Geodetic Survey System - Second Interim

Technical Report, A

Study to Optimize Performance of the Rapid

Geodetic Survey System - Addendum Report, A

Subterranean Detection and Analysis (SDA) (U)

Surface Climate of the Arctic Basin

Surface Gravity Effects of Subterranean Tunnels
REPORT NO.

YEAR

AD 676849

1968

1352-TR

1954

ETL-CR-71-19

1956-1957

1971

AD $486467 \mathrm{~L} \quad 1966$

ETL-CR-73-14

1973

ETL-CR-73-14

1973

ETL-CR-72-17

1972

AD 722790

1969

ETL-0271

1981

ETL-0070

1976

ETL-CR-74-7

1974

AD 505912

1969

ETL-CR-71-24

1971

ETL-0252

1981

ETL-0264

1981

ETL-0321

1983

TEC-S-0001

1991

ETL-TR-71-5

1971

ETL-0069 


\section{TITLE}

Surface Materials and Terrain Features of Yuma Proving Ground, Part I Summary Description

Survey of Digital Image Display Systems (Soft Copy)

Survey of Digital Image Scanning Systems

Survey of Display Devices (Hard Copy)

Survey of Mass Storage Systems

Surveying Instrument: Azimuth, Gyro, Lightweight (SIAGL) (Lear Siegler, Inc.)

Symbolic Model-Based SAR Feature Analysis and Change Detection

Synthesis Guide for Cross-Country Movement

(Report No. 4 in the ETL Series on Guides for Army Terrain Analysts)

Synthesis Guide for Helicopter Landing Zone and Drop Zone Sites

Synthesis Guide for Lines of Communication

(Report No. 7 in the ETL Series on Guides for Army Terrain Analysts)

Synthesis Guide for Obstacle Siting

(Report No. 9 in the ETL Series on Guides

for Army Terrain Analysts)

Synthesis Guide for River Crossings

(Report No. 11 in the ETL Series on Guides for Army Terrain Analysts)

System Analysis of the Entire Topographic

Support System

System Analysis of the Entire Topographic

Support System (TSS), Final Report

System Analysis of the Entire Topographic

Support System (TSS), Interim Report

System and Design Study for an Advanced Drum

Plotter

System for Automatic Secure Transmission and

Reception of Topographic Information - Maps,

Photographs, or Alphanumeric Facsimile - at

TV Rates

System for Topographic Inquiry - No. 1,

Micrographic Subsystem

System for Topographic Inquiry - No. 2,

Alphanumeric Subsystem

System for Topographic Inquiry - No. 3,

Alphanumeric Subsystem Data Base Listing

System for Topographic Inquiry - No. 4,

Program Conversion Procedures
REPORT NO.

YEAR

ETL-0021

1975

ETL-0085

1976

ETL-0087

1976

ETL-0086

1976

ETL-0082

1975

ETL-TR-72-2

1972

TEC-0010

1992

ETL-0220

1980

ETL-0401

1985

ETL-0263

1981

ETL-0283

1982

ETL-0344

1983

ETL-0390

1985

ETL-0158-2

1978

ETL-0158-1

1978

ETL-CR-70-3

1970

ETL-CR-71-2

1971

ETL-ETR-74-2 1974

ETL-0003

1975

ETL-0004

1975

ETL-0005

1975 
System for Topographic Inquiry - No. 5,

ETL-0031

1975

Alphanumeric Subsystem Users Guide

AD $476273 L \quad 1965$

Systematic Correction and Weighing of Analogue

AD $482852 \mathrm{~L}$

1966

Aerial Triangulation Observations and Their

Use in Strip and Block Adjustments

Systematic Investigations of Geodetic Networks in Space, Interim

Systematic Investigations of Geodetic Networks

AD 815717

1967 in Space, Final

Systems Concepts for Military Geographic Intelligence, Vol. I

Tactical/Strategic Point Positioning Study

Target Location Errors Derived From a Hypothetical Target Tracking System

Technical Data on KC-Film, Toners, and Processes

Technical Report for Automatic Line Follower

Techniques to Improve Astronomic Positioning in the Field

Technology Requirements for Minefield Detection from Space

Television Display of Topographic Information

Television Display of Topographic Information, Phase II

Terrain Analysis Procedural Guide for Built-Up Areas (Report No. 13 in the ETL Series on Guides for Army Terrain Analysts)

Terrain Analysis Procedural Guide for Climate (Report No. 5 in the ETL Series on Guides for Army Terrain Analysts)

Terrain Analysis Procedural Guide for Drainage and

ETL-0319

1981

ETL-0531

ETL-0224

1980

ETL-CR-72-18 1972

ETL-0400

1985

TEC-0056

1994

ETL-CR-70-7

1970

ETL-CR-71-23

1971

ETL-0352

1984

ETL-0247

1980

Water Resources (Report No. 8 in the ETL

ETL-0285

1982 Series on Guides for Army Terrain Analysts)

Terrain Analysis Procedural Guide for Geology

ETL-0207

1979 (Report No. 3 in the ETL Series on Guides for Army Terrain Analysts)

Terrain Analysis Procedural Guide for Railroads (Report No. 10 in the ETL Series on Guides for Army Terrain Analysts)

Terrain Analysis Procedural Guide for Roads

ETL-0205

1979 and Related Structures (Report No. 2 in the ETL Series on Guides for Army Terrain Analysts)

Terrain Analysis Procedural Guide for Soil

ETL-0254

1981

(Report No. 6 in the ETL Series on Guides for Army Terrain Analysts) 


\section{TITLE}

Terrain Analysis Procedural Guide for Surface Configuration (Report No. 12 in the ETL Series on Guides for Army Terrain Analysts)

Terrain Analysis Procedural Guide for Vegetation (Report No. 1 in the ETL Series on Guides for Army Terrain Analysts)

Terrain Analyst Synthesizer Station

Terrain Analyst Work Station (TAWS): 1AD After Action Report

Terrain Data of Mount Hayes D-4 Quadrangle, Fort Greely, Alaska (Report No. 4 in the ETL Series on Remote Sensing)

Terrain Effects Analysis Routine for an MGI System

Terrain Eigenvector Dyad Analysis

Terrain Factor Analysis and Automatic Color Coded Mapping Utilizing the IDECS

Terrain Modeling: Shortest Path, Drain Patterns, and Interspersed Contours

Terrain Visualization for the Portable All-Source Analysis Work Station

Test and Evaluation of a Baudot-FIELDATA Code Converter, Paper Tape

Test and Evaluation of 9 by 18 Rectifier for 12- and 24-inch Focal Length Photography

Test and Evaluation of Target Map Coordinate Locator Equipment

Test and Evaluation of the Analytical Photogrammetric Positioning System, Advanced (APPS-II)

Test and Evaluation of the Direct Viewing Stereoplotter, Wernstedt-Mahan Type

Test and Evaluation of the Headliner, Model 400

Test and Evaluation of the Interim Halcon Mapping System

Test and Evaluation of the Interim Stereoplotter, Topographic, Projection Type, High Precision

Test and Evaluation of the Kelsh Plotter, Model 5000, Manufactured by the Instruments Corp.

Test and Evaluation of the Near Real Time Exploitation System

Test and Evaluation of the Prototype Side-Looking Radar Restitutor

Test and Evaluation of the Santoni Cartographic Stereomicrometer
REPORT NO.

YEAR

ETL-0352

1984

ETL-0178

1979

ETL-0231

1980

ETL-0470

1987

ETL-TR-74-7

1974

ETL-0010

1975

AD 649347

1967

ETL-CR-72-13

1972

TEC-0003

1991

TEC-0011

1992

15-TR

1963

1460-TR

1956

14-TR

1963

ETL-0293

1982

1471-TR

1957

1568-TR

1959

3-TR

1961

1493-TR

1957

1311-TR

1953

ETL-0281

1982

29-TR

1966

1644-TR

1960 
TITLE

Test and Evaluation of the 720 Plotter

Manufactured by Bausch and Lomb Optical Co.

Test and Evaluation of the Stereopontometer and Adapted Multiplex

Test and Evaluation of the Stereopontometer with

Kelsh Type Stereoplotters

Test and Evaluation of Ultrasonic Scribing Equipment

Test and Investigation of the Photonymograph $(\mathrm{PN}-4)$

Test of Map-Read Magnetic Declination Accuracy

Test of Reconnaissance Photographic Transposer MAN/GSH-1

Test Results of a Singer, Kearfott Division

Modified Land Navigation System

Test Results of the Lear Siegler, Singer and Sperry Gyro Heading Reference Systems

Test Results of the Litton Low-Cost SemiStrapped-Down Inertial Land Navigation System

Test Strategy for High Resolution Image Scanners, A

Testing and Evaluation of the Shiran System by Advanced Data Reduction Methods

Testing of an Experimental Viscous-Friction Coupled Small North Orienting Device

Tests and Evaluation of an Automatic Point Reading, Plotting, and Grid Ruling Machine

Tests and Evaluation of an Earth Curvature Correction Device

Tests and Evaluation of the AS-11A Stereoplotter

Tests and Evaluation of the Zeiss Stereotype Stereoplotting Instrument

Tests and Evaluation of Ultrawide-Angle Mapping Photography

Tests and Evaluations of Precision

Coordinatographs

Tests of Basic Geometrical Qualities of

Photogrammetric Plotting Instrument

Tests on the Change Detector

Texture Analysis and Cartographic Feature Extraction

Texture Tone Study - Category Maps, Gradient and Homogeneity Images

Texture Tone Study - Classification Experiments

Texture Tone Study (Quantizing on the IDECS/PDP)

Texture Tone Study: Summary and Evaluation
REPORT NO.

YEAR

1348-TR

1954

1381-TR

1954

1425-TR

1955

1641-TR

1960

1537-TR

1958

ETL-148

1978

1566-TR

1959

ETL-0238

1980

ETL-0288

1982

ETL-0202

1979

ETL-0345

1983

AD 707418

1969

AD 822011

1967

8-TR

1962

10-TR

1963

50-TR

1969

1567-TR

1959

6-TR

1961

1-TR

1961

RN-5

1962

1964

ETL -0370

1985

ETL-CR-73-10

1973

ETL-CR-72-16

1972

ETL-CR-72-3

1972

ETL-0005 


\section{TITLE}

Texture Tone Study with Application to Digitized Imagery

Texture Tone Study with Application to Digitized Imagery (Interim Report)

Texture Tone Study with Application to Digitized Imagery (Final Report)

Theodolite with Shaft Angle Encoder and Display

Theoretical and Experimental Study of Wave

Scattering from Composite Rough Surfaces

Thermal Infrared Spectra of Natural and Man-Made

Materials: Implications for Remote Sensing

Third-Order Co-Occurrence Texture Analysis

Applied to Samples of High Resolution

Synthetic Aperture Radar Imagery

Three Approximate Methods for Estimating the Best Subset of GPS Satellites Position Calculations

3-D Road Structure from Motion Stereo

Tight Upper Bound for the Speed-Up of Parallel

Best-First Branch-and-Bound Algorithms, A

Topographic Data Output Study

Topographic Eigenvector Analysis

Topographic Radar Mapping Systems Design Study

Topographic Relaxation Study

Total Optical Color System (Report No. 2

in the ETL series on Remote Sensing)

Toward Automatic Extraction of Cartographic Features

TPLOT: A Simple Program for Plotting Percent Composition Data on Ternary Diagrams

Training Course on Data Reduction of Radar Topographic Imagery

Transformation of Coordinates of Cartographic Digital Data

Transformations for Dimension Reduction and

Expansion of the Discrete Fourier Transform Under Scanning

Transforming Printers: Acceptance and Engineering Tests

Transitional Design Study of the Position and Azimuth Determining System (PADS)

Tribrach, Universal

Tripod, Universal, Final Report on Project 8-35-10-107

Two Approaches to a Portable Color-Measuring System
REPORT NO.

YEAR

TR-182-1

1970

ETL-CR-71-14

1971

ETL-CR-74-17

1974

AD 662080

1967

ETL-CR-74-4

1974

ETL-0587

ETL-0396

1985

ETL-0556

1990

ETL-0471

1987

ETL-0462

1987

AD 262 161L 1961

AD $484747 \mathrm{~L} \quad 1966$

ETL-0209

ETL-ETR-74-3

ETL-0153

1978

ETL-RN-74-2

1973

AD 721653

1969

ETL-TR-74-8

1974

ETL-RN-74-3

1974

40-TR

1968

ETL-0001

1975

1453-TR

1956

1413-TR

1955

RN-15

1966 


\section{TITLE}

Two Dimensional Path Planning with Obstacles and Shadows

Two-Way Linear Interpolation

Type I Geodetic Satellite

Typro Composer Photolettering Machine

Unified Approach to Mapping, Charting, and Geodesy (MC\&G) Data Base Structure Design

Unified Geodetic Parameter Program (GEOPS), Vol. 1 of 2 - Mathematical Analysis

Unified Geodetic Parameter Program (GEOPS), Vol. 2 of 2 - Program Description

Universal Analog Rectification System for Map Revision

Universal Automatic Map Compilation Equipment

Universal Radar Signal Processor (Correlator), Interim

Universal Radar Signal Processor (Correlator), Final

Urban Warfare Digital Database SBIR Phase I

U.S. Army Evaluation of the Electronic Map Data (EMD) Prototype

U.S. Army Type II Geodetic Satellites, Vol. 1

U.S. Army Type II Geodetic Satellites, Vol. 2

U.S. Army Type II Geodetic Satellites, Vol. 3

Use and Calibration of Distance Measuring

Equipment for Precise Mensuration of Dams (Revised)

Use and Calibration of Distance Measuring Equipment for Precise Mensuration of Dams

Use of a Vidicon to Digitize Certain Types of Target Image in a Photographic Background

Use of Array Algebra in Terrain Modeling Procedures

Use of Edges of Photographic Images as Specifiers of Image Quality

Use of Interim Terrain Data to Populate Project 2851's Database in Support of Ground Forces Simulation

Use of Radar Images in Terrain Analysis: An Annotated Bibliography

Use of Side-Looking Airborne Radar (SLAR) Imagery for Engineering Soils Studies

User's Guide for the Analytical Photogrammetric Positioning System (APPS), A

User's Guide to Data Preparation, Photogrammetric Navigation Analysis Program Fotonap
REPORT NO.

YEAR

ETL-0452

1987

ETL-RN-71-5

1971

AD 721652

1964

1504-TR

1957

ETL-0144

1978

AD 640321

1966

AD 640322

1966

24-TR

1965

51-TR

1969

AD 487 144L

1966

AD 841 545L

1968

TEC-0042

1992

TEC-0026

1992

AD 721645

1965

AD 721646

1965

AD 721647

1965

ETL-0048

1976

ETL-0190

1979

AD 457 818L

1964

ETL-0094

1976

ETL-CR-72-15

1972

ETL-0591

1991

ETL-0024

1975

46-TR

1969

ETL-0446

1986

ETL-0174

1978 
TITLE

User's Manual for the Reference Scene Software (RSS)

Using Terrain Analysis to Predict Likely Minefield Sites

Utility of Radar Imagery in the Production of Tactical Terrain Data. Military

Capabilities Report

Utilization of a Photogrammetric Facility (PF) in Human Engineering Laboratories Battalion Artillery Test Number Two (HELBAT II)

Variscale Stereo Point Marking Instrument

Vegetation and Terrain Effects on Digital Classification of LANDSAT Imagery

Vegetation and Terrain Relationships in South-Central New Mexico and Western Texas

Vegetation Data Extraction Software

Documentation/User's Manual

Vegetative Cover Effects on Soil Spectral Reflectance

Vertical Obstruction Study, Final Report

Video Stream Processors: A Cost-Effective Computational Architecture for Image Processing

Vision-Based Navigation and Parallel Computing First Annual Report

Vision-Based Navigation and Recognition

Visual Factors Affecting the Precision of Coordinate Measurement in Aerotriangulation

Visual Navigation System for Autonomous Land Vehicles, A

Vision-Based Navigation and Parallel Computing Second Annual Report

Vision-Based Navigation for Autonomous Ground Vehicles, Fourth Annual Report

Vision-Based Navigation for Autonomous Ground Vehicles, 1986 Annual Report

Vision-Based Navigation for Autonomous Ground Vehicles, First Annual Report

Vision-Based Navigation for Autonomous Ground Vehicles, Third Annual Report

Vision-Based Navigation for Autonomous Ground Vehicles, Summary Report

Voice Interactive Systems Technology (VIST) Research

Voice Interactive Systems Technology (VIST) Research
REPORT NO.

ETL-0066

ETL-0325

ETL-0045

ETL-SR-71-2

1971

39-TR

1968

ETL-0292

1982

ETL-0245

1980

ETL-0340

1983

ETL-0284

1982

ETL-0358

1984

ETL-0229

1980

ETL-0548

1989

TEC-0047

RN-21

1994

1967

ETL-0408

1985

ETL-0572

1990

TEC-0028

1992

ETL-0432

1986

ETL-0509

1988

ETL-0519

1988

ETL-0543

1989

ETL-0349

1984

ETL-0349

1984 


\section{TITLE}

Water Resources Overlays Users Guide

Weather Extremes Around the World (Revision of NLABS Report TR-70-45-ES)

Weighted Line-Finding Algorithm

What is a Hill? An Analysis of the Meaning of Generic Topographic Terms

Wind Design Criteria for Field Shelters - A Study

Wire List GEISHA Computer

World Areas More Humid Than the Canal Zone during the Wet Season (Note 3 of "Studies to

Aid TECOM in Analyses of Environmental Risks to Materiel")

World Areas with Higher Precipitation Intensities and Frequencies than the Tropic Test Center, Canal Zone

World Areas with Higher Temperatures than the Yuma Proving Ground During Summer (Note 2 of "Studies to Aid TECOM in Analyses of Environmental Risks to Materiel")

World Areas with Lower Temperatures than the Arctic Test Center During Winter (Note 1 of "Studies to Aid TECOM in Analyses of Environmental Risks to Materiel")

World Weather Extremes

Worldwide Distributions of Ambient Temperatures and Temperatures of Materiel Exposed to Direct Solar Radiation

Worldwide Distribution of Mean Dewpoint: Surface and Lower Atmosphere

Worldwide Distribution of Mean Monthly Dewpoint (Supplement to ETL-SR-72-4 "Worldwide Distributions of Mean Dewpoint: Surface and Lower Atmosphere")

Xerox 6500 Color Copier

Zoom Transfer Scope
ETL-0106

1977

REPORT NO.

YEAR

TEC-SR-3

1990

ETL-TR-74-5

1974

ETL-0200

1979

ETL-0576

1991

ETL-0037

1975

AD 847667

ETL-RN-74-8

1969

1974

ETL-0022

1975

ETL-RN-74-6

1974

ETL-RN-74-5

1974

ETL-0416

1985

ETL-SR-73-2

1972

ETL-SR-72-4

1972

ETL-SR-72-2

1973

ETL-ETR-72-5

1972 